- 98- 九州歯会誌・第 24 巻第 I号 (1970)

\title{
老人ホーム入居者う霜加療の統計的研究
}

九州歯科大学口腔衛生学教室 (指導 : 荷宮文夫教授)

松尾梅雄 - 一田尚利 - 宮田英一

鍛治口香・清川幸雄・前田義信

（昭和45年 3 月30日受理）

\section{A STATISTIC STUDY ON DENTAL CARE STATUS AMONG RESIDENTS IN A SANATORIUM FOR THE AGED}

\author{
By \\ Umeo MATSUO, Hisatoshi ICHIDA, Eiichi MIYATA, Kaoru KAJIGUCHI \\ Yukio KIYOKAWA and Yoshinobu MAEDA \\ Department of Preventive Dentistry (Director : Prof. Fumio NINOMIYA) \\ Kyushu Dental College, Kitakyushu, Japan
}

A survey was undertaken on the status of dental care which the residents of a sanatorium ranged in age from 50 to 95 years had received. Study was conducted on the total number of denture teeth, metallic crown and fillings in each quadrant of mouth and the data obtained were analyzed statistically with reference to sex and age of the subjects. Results were summarized as follows.

1. Ratio of denture teeth versus FT (\%) : Sex difference was not marked with respect to the rates for all the teeth involved. The rates increased with advancing age of the subjects of both sexes until about 50 to $100 \%$ of FT were replaced by denture teeth.

2. Ratio of metallic crown teeth versus FT $(\%)$ : With both sexes, metallic crown occupied 20 to $0 \%$ of FT which decreased with advancing age of subjects. No marked difference was noticed between sexes in this respect.

3. Ratio of filled teeth versus FT (\%) : The rates were extremely small for all the teeth in both sexes, and there was hardly difference with advancing age of the subjects.

4. Ratio of $\mathrm{MT} \rightarrow \mathrm{FT}$ versus MT (\%) : With both sexes, 60 to $50 \%$ of missing teeth were left untreated teeth of both jaws, regardless of sexes.

5. Ratio of teeth suffering periodontal diseases existing teeth(\%): Teeth of lower versus jaw showed higher rate than teeth of upper jaw with both subjects when compared between the same named teeth of both jaws. No age difference was noticed in this respect. 


\section{ま え がき}

永久䨑う歯の加療状態についての研究は，比較的に少 ない，教室に㧍いては，荷宮・他（1942）1）が日満兵員 について報告し，大和（1954）2）筑豊の炭坑彷業員に ついて，柿沼（1960） 3）は大分県一尺屋部落之下関市工 場街の住民について，満下（1963）4）は福岡市成人につ いて報告している．滝口（1969）5）は福岡県下42の老人 ホームに居住しているもののう菌について報告した。滝 口5) の同一資料を用いて，う歯の加療歯について上下顎 各霜別に年令層別に観察した。成績の概要を報告する，

\section{対 象}

研究に用いた対象は，滝口5) の用いた福岡県下42の老 人ホームに入居している50才〜95才の男835人，女 1185 人, 合計 2020 人である. 男女別年令層別人数は, 表 $1 の$ 通りである.

表 I年 令 群 別人 数

\begin{tabular}{|c|c|c|c|}
\hline 年 & 令 & 男 & 女 \\
\hline 50 & $\sim 60$ & 32 & 40 \\
\hline 60 & $\sim 70$ & 270 & 294 \\
\hline 70 & $\sim 80$ & 402 & 560 \\
\hline 80 & $\sim 90$ & 123 & 275 \\
\hline 90 & $\sim 95$ & 8 & 16 \\
\hline \multirow{2}{*}{\multicolumn{2}{|c|}{ 計 }} & 835 & 1185 \\
\hline & & \multicolumn{2}{|c|}{2020} \\
\hline
\end{tabular}

\section{観 察 項 目}

対象を年令10才階級に区分し，男女別各年代別に，智 歯を除いた上下顎14歯の各歯別に観察した。加療歯 $\mathrm{F} \mathrm{T}$
の内訳を義㐘, 金属冠㐘, 充填歯にわけ, 各々が F T 対する百分比之, その標準偏差を出した。男女間の比率 の差を比較した。

\section{成}

\section{1. 義菡 $/ \mathrm{F} \mathrm{T}$ 率 $(\%)$}

男女別年代別上下顎永久歯の各歯別に，F T 数に対す る義歯数の割合は，表 $2 \sim 5$ の通りである.

上 顎

中切夹：男の50才代は85\%で増令につれて増し，90才 代には $100 \%$ となっている．女は50才代には70.3\%で80 才代に96.6\%に増している. 男女間の差はほとんどな い.

側切料：男は91.7\%〜100.0\%，女は81.8\%〜100.0\% で増令につれわずかに増率し，男女間の差はほとんどな い.

犬篓：男は87.5\%〜100.0\%，女は86.7\%〜100.0\%で 増令につれてわずかに増し，男女間の差はほとんどな w.

第一小曰歯：男は 84.6\%〜100.0\%，女は $77.4 \%$ $100.0 \%$ で増令につ机て增し, 男女間の差は著しくな w.

第二小曰霜：男は $80.8 \%$ 100.0\%，女は $96.3 \%$ $100.0 \%$ で男女と屯増令につれてわずかに増し，男女間 の差はほとんどない.

第一大臼電：男は 85.2\%〜 $100.0 \%$ ，女は $96.2 \%$ $100.0 \%$ で増令につれてわずかに増し，男女間の差はほ とんどない.

第二大四歯：男は85.7\%〜 100.0\%, 女は 92.3\%〜 100.0\%で，男女子あ増令につれてわずかに増してい

\begin{tabular}{|c|c|c|c|c|c|c|c|c|c|c|c|c|}
\hline \multirow{2}{*}{ 歯 } & \multirow{2}{*}{ 年 令 層 } & \multicolumn{4}{|c|}{ 男 } & \multicolumn{4}{|c|}{ 女 } & \multicolumn{2}{|c|}{ 男 } & \multirow{2}{*}{$\frac{\text { 女 }}{\mathrm{d} / \mathrm{Sd}}$} \\
\hline & & F T & 義歯 & $\mathrm{p}(\%)$ & $\mathrm{Sp}(\%)$ & F T & 義菌 & p (\%) & $\mathrm{Sd}(\%)$ & $\mathrm{d}(\%)$ & Sd $(\%)$ & \\
\hline \multirow{6}{*}{1} & $50 \sim 60$ & 27 & 23 & 85.18 & 6.84 & 37 & 26 & 70.27 & 7. 52 & 14.91 & 10.14 & 1.470 \\
\hline & $60 \sim 70$ & 229 & 210 & 91.70 & 1.82 & 307 & 268 & 87.30 & 1.90 & 4. 40 & 2.63 & 0.167 \\
\hline & $70 \sim 80$ & 371 & 339 & 91.37 & 1.46 & 647 & 598 & 92.43 & 1.04 & -1.06 & 1.79 & -0.592 \\
\hline & $80 \sim 90$ & 114 & 104 & 91.22 & 2.65 & 294 & 284 & 96.60 & 1.06 & -5.38 & 2.85 & -1.887 \\
\hline & $90 \sim 95$ & 2 & 2 & 100.00 & 0 & 18 & 16 & 88.89 & 7.41 & 11.11 & 7.41 & 1.499 \\
\hline & $\mathrm{MR} / \mathrm{S}_{\mathrm{MR}}$ & & & & & & & & & & & 0.263 \\
\hline
\end{tabular}


老人ホーム入居者う雬加療の統計的研究

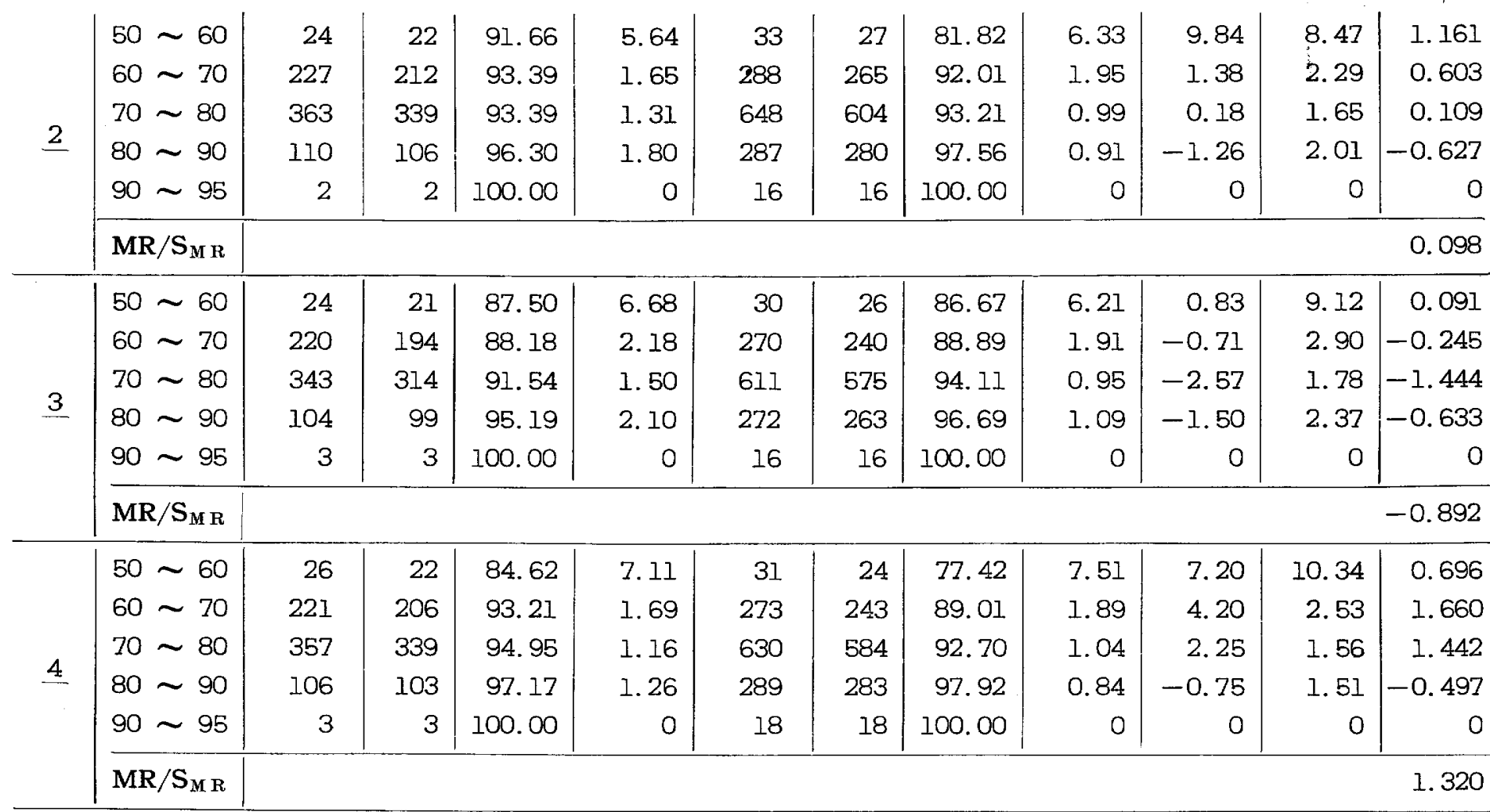

表 3

男女別年代別歯別（義雪/F T ）率とその差

(\%)

\begin{tabular}{|c|c|c|c|c|c|c|c|c|c|c|c|c|}
\hline \multirow{2}{*}{ 歯 } & \multirow{2}{*}{ 年 令 層 } & \multicolumn{4}{|c|}{ 男 } & \multicolumn{4}{|c|}{ 女 } & \multicolumn{2}{|l|}{ 男 } & 女 \\
\hline & & F T & 義䨑 & $\mathrm{p}(\%)$ & Sp (\%) & $\mathrm{F} \mathrm{T}$ & 義歯 & p (\%) & $\mathrm{Sp}(\%)$ & $\mathrm{d}(\%)$ & Sd $(\%)$ & $\mathrm{d} / \mathrm{Sd}$ \\
\hline \multirow{6}{*}{$\underline{5}$} & $50 \sim 60$ & 26 & 21 & 80.77 & 7.73 & 27 & 26 & 96.30 & 3.63 & -15.53 & 8.54 & -1.818 \\
\hline & $60 \sim 70$ & 233 & 213 & 90.41 & 1.93 & 273 & 249 & 91.21 & 1.71 & -0.72 & 2.58 & -0.279 \\
\hline & $70 \sim 80$ & 353 & 332 & 94.05 & 1.89 & 638 & 603 & 94.51 & 0.90 & -0.46 & 2.09 & -0.220 \\
\hline & $80 \sim 90$ & 109 & 105 & 96.32 & 1.81 & 290 & 282 & 97.24 & 0.96 & -0.92 & 2.05 & -0.449 \\
\hline & $90 \sim 95$ & 4 & 4 & 100.00 & 0 & 18 & 18 & 100.00 & 0 & 0 & 0 & 0 \\
\hline & $\mathrm{MR} / \mathrm{S}_{\mathrm{MR}}$ & & & & & & & & & & & -1.106 \\
\hline \multirow{6}{*}{$\underline{6}$} & $50 \sim 60$ & 27 & 23 & 85.18 & 6.84 & 26 & 25 & 96.15 & 3. 77 & -10.97 & 7.81 & -1.404 \\
\hline & $60 \sim 70$ & 241 & 210 & 87.14 & 2.16 & 261 & 239 & 91.57 & 1.72 & -4.43 & 2.76 & -1.605 \\
\hline & $70 \sim 80$ & 368 & 348 & 94.56 & 1.18 & 632 & 609 & 96.36 & 0.75 & -1.80 & 1. 40 & -1.285 \\
\hline & $80 \sim 90$ & 109 & 106 & 97.25 & 1.57 & 290 & 282 & 97.24 & 0.96 & 0.01 & 1.84 & 0.005 \\
\hline & $90 \sim 95$ & 4 & 4 & 100.00 & 0 & 18 & 18 & 100.00 & 0 & 0 & 0 & o \\
\hline & $\mathrm{MR} / \mathrm{S}_{\mathrm{MR}}$ & & & & & & & & & & & -1.716 \\
\hline \multirow{6}{*}{$\underline{7}$} & $50 \sim 60$ & 28 & 24 & 85.71 & 6.61 & 26 & 24 & 92.31 & 5. 23 & -6.60 & 8.43 & -0.783 \\
\hline & $60 \sim 70$ & 227 & 214 & 94.27 & 1.54 & 268 & 258 & 96.27 & 1. 16 & -2.00 & 1.93 & -1.036 \\
\hline & $70 \sim 80$ & 362 & 344 & 95.02 & 1.14 & 622 & 604 & 97.11 & 0.68 & -2.09 & 1.33 & -1.571 \\
\hline & $80 \sim 90$ & 110 & 105 & 95.44 & 1.99 & 287 & 281 & 97.91 & 0.85 & -2.47 & 2.16 & -1.144 \\
\hline & $90 \sim 95$ & 4 & 4 & 100.00 & 0 & 18 & 18 & 100.00 & 0 & 0 & 0 & 0 \\
\hline & $\mathrm{MR} / \mathrm{S}_{\mathrm{MR}}$ & & & & & & & & & & & -1.814 \\
\hline
\end{tabular}




$1 \quad$\begin{tabular}{r|r|r|r|r|r|r|r|r|r|r|r}
$50 \sim 60$ & 20 & 17 & 85.00 & 7.99 & 24 & 18 & 75.00 & 8.84 & 10.00 & 11.95 & 0.836 \\
$60 \sim 70$ & 172 & 164 & 95.34 & 1.61 & 243 & 219 & 90.12 & 1.91 & 5.22 & 2.50 & 2.088 \\
$70 \sim 80$ & 323 & 298 & 92.26 & 1.49 & 551 & 519 & 94.19 & 1.00 & -1.93 & 1.79 & -1.078 \\
$80 \sim 90$ & 103 & 101 & 98.05 & 1.36 & 270 & 266 & 98.52 & 0.74 & -0.47 & 1.54 & -0.305 \\
$90 \sim 95$ & 4 & 4 & 100.00 & 0 & 14 & 14 & 100.00 & 0 & 0 & 0 & 0 \\
\hline MR/S & & &
\end{tabular}

表 4

男女別年代別㐘別（義蒾/F T) 率とその差

(\%)

\begin{tabular}{|c|c|c|c|c|c|c|c|c|c|c|c|c|}
\hline \multirow{2}{*}{ 雪 } & \multirow{2}{*}{ 年 令 層 } & \multicolumn{4}{|c|}{ 男 } & \multicolumn{4}{|c|}{ 女 } & \multicolumn{2}{|l|}{ 男 } & 女 \\
\hline & & F T & 義柬 & $\mathrm{p}(\%)$ & Sp (\%) & F T & 義歯 & $\mathrm{p}(\%)$ & $\mathrm{Sp}(\%)$ & $\mathrm{d}(\%)$ & Sd (\%) & $\mathrm{d} / \mathrm{Sd}$ \\
\hline \multirow{6}{*}{2} & $50 \sim 60$ & 21 & 18 & 85.71 & 7.64 & 24 & 17 & 70.83 & 9.28 & 14.88 & 12.02 & 1.237 \\
\hline & $60 \sim 70$ & 163 & 155 & 90.09 & 2.34 & 218 & 191 & 87.61 & 2. 23 & 2.48 & 3. 23 & 0.768 \\
\hline & $70 \sim 80$ & 315 & 287 & 91.11 & 1.61 & 548 & 517 & 94.34 & 0.99 & -3.23 & 1.89 & -1.708 \\
\hline & $80 \sim 90$ & 102 & 100 & 98.04 & 1.38 & 268 & 264 & 98.51 & 0.74 & -0.47 & 1.57 & -0.299 \\
\hline & $90 \sim 95$ & 4 & 4 & 100.00 & 0 & 15 & 15 & 100.00 & 0 & 0 & 0 & 0 \\
\hline & $\mathrm{MR} / \mathrm{S}_{\mathrm{M} \mathrm{R}}$ & & & & & & & & & & & 0 \\
\hline \multirow{6}{*}{3} & $50 \sim 60$ & 20 & 15 & 75.00 & 9.68 & 23 & 18 & 78.26 & 8.60 & -3.26 & 12.95 & -0.252 \\
\hline & $60 \sim 70$ & 132 & 116 & 87.88 & 2.84 & 214 & 194 & 90.65 & 1.99 & -2.77 & 3. 47 & -0.798 \\
\hline & $70 \sim 80$ & 278 & 246 & 88.48 & 1.91 & 517 & 475 & 91.88 & 1.20 & -3.40 & 2.25 & -1.511 \\
\hline & $80 \sim 90$ & 94 & 88 & 93.62 & 2.52 & 257 & 247 & 96.11 & 1.20 & -2.49 & 2.79 & -0.892 \\
\hline & $90 \sim 95$ & 4 & 3 & 75.00 & 21.65 & 14 & 0 & 100.00 & 0 & -25.00 & 21.64 & -1.155 \\
\hline & $\mathrm{MR} / \mathrm{S}_{\mathrm{MR}}$ & & & & & & & & & & & -1.840 \\
\hline \multirow{6}{*}{4} & $50 \sim 60$ & 23 & 19 & 82.61 & 7.90 & 27 & 19 & 70.37 & 8.79 & 12.24 & 11.81 & 1.036 \\
\hline & $60 \sim 70$ & 172 & 150 & 87.21 & 2.54 & 239 & 210 & 87.87 & 2.11 & -0.66 & 3.31 & -0.199 \\
\hline & $70 \sim 80$ & 317 & 288 & 90.85 & 1.62 & 556 & 513 & 92.27 & 1.14 & -1.42 & 1.99 & -0.717 \\
\hline & $80 \sim 90$ & 104 & 90 & 86.54 & 3.35 & 255 & 241 & 94.51 & 1.43 & -7.97 & 3.64 & -2.189 \\
\hline & $90 \sim 95$ & 5 & 4 & 80.00 & 17.88 & 15 & 15 & 100.00 & 0 & -20.00 & 18.43 & -1.085 \\
\hline & $\mathrm{MR} / \mathrm{S}_{\mathrm{MR}}$ & & & & & & & & & & & -1.230 \\
\hline \multirow{6}{*}{5} & $50 \sim 60$ & 27 & 21 & 77.77 & 8.00 & 28 & 23 & 82.14 & 7.24 & -4.37 & 10.78 & -0.405 \\
\hline & $60 \sim 70$ & 204 & 184 & 90.19 & 2.08 & 248 & 220 & 88.71 & 2.01 & 1.48 & 2.89 & 0.512 \\
\hline & $70 \sim 80$ & 344 & 312 & 90.69 & 1.50 & 576 & 538 & 93.40 & 0.33 & -2.71 & 1.59 & -1.704 \\
\hline & $80 \sim 90$ & 106 & 98 & 92.45 & 2. 56 & 265 & 253 & 95.47 & 1.28 & -3.02 & 2.86 & -1.055 \\
\hline & $90 \sim 95$ & 4 & 4 & 100.00 & 0 & 15 & 15 & 100.00 & 0 & 0 & 0 & 0 \\
\hline & $\mathrm{MR} / \mathrm{S}_{\mathrm{MR}}$ & \multicolumn{11}{|r|}{-1.068} \\
\hline
\end{tabular}




\begin{tabular}{|c|c|c|c|c|c|c|c|c|c|c|c|c|}
\hline \multirow{2}{*}{ 歯 } & \multirow{2}{*}{ 年 令 層 } & \multicolumn{4}{|c|}{ 男 } & \multicolumn{4}{|c|}{ 女 } & \multicolumn{2}{|c|}{ 男 } & 女 \\
\hline & & F T & 義㐘 & p (\%) & $\mathrm{Sp}(\%)$ & F T & 義歯 & $\mathrm{p}(\%)$ & $\mathrm{Sp}(\%)$ & d $(\%)$ & Sd $(\mathscr{\%})$ & $\mathrm{d} / \mathrm{Sd}$ \\
\hline \multirow{6}{*}{6} & $50^{\circ} \sim 60$ & 28 & 24 & 85.71 & 6.61 & 31 & 24 & 77.42 & 7.51 & 8.29 & 10.01 & 0.828 \\
\hline & $60 \sim 70$ & 207 & 186 & 89.86 & 2. 10 & 256 & 230 & 89.84 & 1.89 & 0.02 & 2.82 & 0.007 \\
\hline & $70 \sim 80$ & 346 & 322 & 93.06 & 1.37 & 582 & 548 & 94.16 & 0.97 & -1.10 & 1.68 & -0.654 \\
\hline & $80 \sim 90$ & 112 & 103 & 91.96 & 2.57 & 271 & 261 & 96.31 & 1.15 & -4.35 & 2.82 & -1.542 \\
\hline & $90 \sim 95$ & 4 & 4 & 100.00 & 0 & 16 & 16 & 100.00 & 0 & 0 & 0 & 0 \\
\hline & $\mathrm{MR} / \mathrm{S}_{\mathrm{M} \mathrm{R}}$ & & & & & & & & & & & -0.544 \\
\hline \multirow{6}{*}{7} & $50 \sim 60$ & 25 & 20 & 80.00 & 8.00 & 28 & 21 & 75.00 & 8.18 & 5.00 & 11.44 & 0.437 \\
\hline & $60 \sim 70$ & 202 & 182 & 90.09 & 2.10 & 256 & 237 & 92.58 & 1.64 & -2.49 & 2.66 & -0.936 \\
\hline & $70 \sim 80$ & 339 & 323 & 95.28 & 1.15 & 556 & 530 & 95.32 & 0.90 & -0.04 & 1.46 & -0.027 \\
\hline & $80 \sim 90$ & 111 & 105 & 94.59 & 2. 15 & 267 & 259 & 97.00 & 1.04 & -2.41 & 2.39 & -1.008 \\
\hline & $90 \sim 95$ & 4 & 4 & 100.00 & 0 & 16 & 16 & 100.00 & o & 0 & 0 & 0 \\
\hline & $\mathrm{MR} / \mathrm{S}_{\mathrm{MR}}$ & & & & & & & & & & & -0.614 \\
\hline
\end{tabular}

る.男女間の差は著しくない。

下 䫴

中切㐘：男は85.0\%〜100.0\%，女は75.0\%〜100.0\% で男女よも増令につれて増し, 男女間の差はほとんに゙な い.

側切蒾：男は85.7\%〜100.0\%,女は70.8\%〜100.0\%， 犬宩：男は75.0\%〜93.6\%，女は 78.3\% 100.0\%.

第一小四歯：男は82.6\%〜86.5\%，女は $70.4 \%$ $100.0 \%$.

第二小曰歯：男は77.8\%〜100.0\%，女は $82.1 \%$
$100.0 \%$.

第一大臼歯男は85.7\%〜100.0\%，女は77.4\%〜100. $\%$.

第二大曰菌：男は $80.0 \%$ 100.0\%，女は $75.0 \%$ 一 100.0\%である.

男女のいずれの歯とあ増令につれて増率し，各歯とま 男女間の差は著しくない。

2. 金属冠歯 $/$ F T 率 $(\%)$

男女別年代別上下顎永久㐘の各菌別の F T 数に対する 金属冠雬数の割合は，表6〜9の通りである. 表6 男女別年代別蒾別（金属冠㐘/F T ）率之その差

$(\%)$

\begin{tabular}{|c|c|c|c|c|c|c|c|c|c|c|c|c|}
\hline \multirow{2}{*}{ 歯 } & \multirow{2}{*}{ 年 令 層 } & \multicolumn{4}{|c|}{ 男 } & \multicolumn{4}{|c|}{ 女 } & \multicolumn{2}{|c|}{ 男 - } & 女 \\
\hline & & F T & 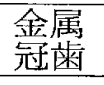 & $\mathrm{p}(\%)$ & $\operatorname{Sp}(\%)$ & $\mathrm{F} \mathrm{T}$ & 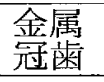 & $\mathrm{p}(\%)$ & $\mathrm{Sp}(\%)$ & $\mathrm{d}(\%)$ & $\operatorname{Sd}(\%)$ & $\mathrm{d} / \mathrm{Sd}$ \\
\hline \multirow{6}{*}{1} & $50 \sim 60$ & 27 & 4 & 14.81 & 6.84 & 37 & 11 & 29.73 & 7.52 & -14.92 & 10.16 & -1.469 \\
\hline & $60 \sim 70$ & 229 & 19 & 8. 29 & 1.82 & 307 & 37 & 12.05 & 1.86 & -3.76 & 2.60 & -1.446 \\
\hline & $70 \sim 80$ & 371 & 26 & 7.01 & 1.32 & 647 & 43 & 6.65 & 0.98 & 0.36 & 1.65 & 0.218 \\
\hline & $80 \sim 90$ & 114 & 7 & 6.14 & 2.25 & 294 & 8 & 2.72 & 0.95 & 3. 42 & 2.44 & 1. 402 \\
\hline & $90 \sim 95$ & 2 & 0 & 0 & 0 & 18 & 2 & 11.11 & 7.41 & -11.11 & 7.41 & -1.499 \\
\hline & $\mathrm{MR} / \mathrm{S}_{\mathrm{M} \mathrm{R}}$ & \multicolumn{11}{|r|}{-1.118} \\
\hline \multirow{6}{*}{2} & $50 \sim 60$ & 24 & 2 & 8.33 & 5.64 & 33 & 6 & 18. 18 & 6.71 & -9.85 & 8.77 & -1.123 \\
\hline & $60 \sim 70$ & 227 & 13 & 5. 73 & 1.54 & 288 & 22 & 7.64 & 1.57 & -1.91 & 2.20 & -0.868 \\
\hline & $70 \sim 80$ & 363 & 22 & 6.06 & 1.26 & 648 & 40 & 6.17 & 0.94 & -0.11 & 2.12 & -0.052 \\
\hline & $80 \sim 90$ & 110 & 4 & 1.64 & 1.21 & 287 & 6 & 2.09 & 0.85 & -0.45 & 1.43 & -0.315 \\
\hline & $90 \sim 95$ & 2 & 0 & 0 & 0 & 16 & 0 & 0 & 0 & 0 & 0 & 0 \\
\hline & $\mathrm{MR} / \mathrm{S}_{\mathrm{MR}}$ & \multicolumn{11}{|r|}{-0.944} \\
\hline
\end{tabular}




$\sim \quad$\begin{tabular}{r|r|r|r|r|r|r|r|r|r|r|r}
$50 \sim 60$ & 24 & 3 & 12.50 & 6.68 & 30 & 3 & 10.00 & 5.48 & 2.50 & 8.64 & 0.289 \\
$60 \sim 70$ & 220 & 22 & 10.00 & 2.02 & 270 & 27 & 10.00 & 1.83 & 0 & 2.73 & 0 \\
$70 \sim 80$ & 343 & 23 & 6.71 & 1.35 & 611 & 30 & 4.91 & 0.87 & 1.80 & 1.61 & 1.118 \\
$80 \sim 90$ & 104 & 4 & 3.85 & 1.96 & 272 & 8 & 2.94 & 1.02 & 0.91 & 2.21 & 0.412 \\
$90 \sim 95$ & 3 & 0 & 0 & 0 & 16 & 0 & 0 & 0 & 0 & 0 & 0 \\
\hline
\end{tabular}

$\mathrm{MR} / \mathrm{S}_{\mathrm{M} \mathrm{R}}$

$\overline{4} \quad$\begin{tabular}{r|r|r|r|r|r|r|r|r|r|r|r}
$50 \sim 60$ & 26 & 4 & 15.38 & 7.11 & 31 & 7 & 22.58 & 7.51 & -7.20 & 11.25 & -0.640 \\
$60 \sim 70$ & 221 & 13 & 5.88 & 1.58 & 273 & 29 & 10.62 & 1.86 & -4.74 & 2.44 & -1.942 \\
$70 \sim 80$ & 357 & 14 & 3.92 & 1.03 & 630 & 43 & 6.83 & 1.00 & -2.91 & 1.44 & $-\mathbf{2 . 0 2 1}$ \\
$80 \sim 90$ & 106 & 2 & 1.89 & 1.32 & 289 & 5 & 1.73 & 0.77 & 0.16 & 1.53 & 0.105 \\
$90 \sim 95$ & 3 & 0 & 0 & 0 & 18 & 0 & 0 & 0 & 0 & 0 & 0 \\
\hline MR/S & & & &
\end{tabular}

\begin{tabular}{|c|c|c|c|c|c|c|c|c|c|c|c|c|}
\hline \multirow{2}{*}{ 歯 } & \multirow{2}{*}{ 年 令 層 } & \multicolumn{4}{|c|}{ 男 } & \multicolumn{4}{|c|}{ 女 } & \multicolumn{2}{|l|}{ 男 } & 女 \\
\hline & & F T & $\begin{array}{l}\text { 金属 } \\
\text { 党米 }\end{array}$ & $\mathrm{p}(\%)$ & $\mathrm{Sp}(\%)$ & F T & $\begin{array}{l}\text { 金属 } \\
\text { 尊幽 }\end{array}$ & p (\%) & Sp (\%) & $\mathrm{d}(\%)$ & Sd $(\%)$ & $\mathrm{d} / \mathrm{Sd}$ \\
\hline \multirow{6}{*}{$\overline{5}$} & $50 \sim 60$ & 26 & 5 & 19.23 & 7.73 & 27 & 1 & 3. 70 & 3.63 & 15.53 & 8.54 & 1.815 \\
\hline & $60 \sim 70$ & 233 & 20 & 8.58 & 1.83 & 273 & 23 & 8.42 & 1.68 & 0.16 & 2.48 & 0.065 \\
\hline & $70 \sim 80$ & 353 & 17 & 4.82 & 1.14 & 638 & 44 & 6.90 & 1.00 & -2.08 & 1.51 & -1.372 \\
\hline & $80 \sim 90$ & 109 & 3 & 2.75 & 1.57. & 290 & 6 & 2.07 & 0.84 & 0.68 & 1.78 & 0.382 \\
\hline & $90 \sim 95$ & 4 & 0 & 0 & 0 & 18 & 0 & 0 & 0 & 0 & 0 & c \\
\hline & $\mathrm{MR} / \mathrm{S}_{\mathrm{MR}}$ & \multicolumn{11}{|r|}{0.356} \\
\hline \multirow{6}{*}{$\underline{6}$} & $50 \sim 60$ & 27 & 3 & 11.11 & 6.05 & 26 & 1 & 3.85 & 3. 77 & 7.26 & 7.13 & 1.018 \\
\hline & $60 \sim 70$ & 241 & 20 & 8.29 & 1. 77 & 261 & 19 & 7.28 & 1.61 & 1.01 & 2.39 & 0.422 \\
\hline & $70 \sim 80$ & 368 & 18 & 4.89 & 1.12 & 632 & 22 & 3. 48 & 0.73 & 1.41 & 1.34 & 1.052 \\
\hline & $80 \sim 90$ & 109 & 3 & 2.75 & 1.57 & 290 & 7 & 2.41 & 0.90 & 0.34 & 1.81 & 0.188 \\
\hline & $90 \sim 95$ & 4 & 0 & o & 0 & 18 & 0 & 0 & 0 & 0 & 0 & c \\
\hline & $\mathrm{MR} / \mathrm{S}_{\mathrm{MR}}$ & \multicolumn{11}{|r|}{1.072} \\
\hline \multirow{6}{*}{7} & $50 \sim 60$ & 28 & 3 & 10.71 & 5.85 & 26 & 1 & 3.85 & 3. 77 & 9.86 & 6.96 & 0.986 \\
\hline & $60 \sim 70$ & 227 & 214 & 4.85 & 1.43 & 268 & 9 & 3. 36 & 1.10 & 1.49 & 1.80 & 0.828 \\
\hline & $70 \sim 80$ & 362 & 14 & 3.87 & 1.01 & 622 & 13 & 2.09 & 0.57 & 1.78 & 1.16 & 1.534 \\
\hline & $80 \sim 90$ & 110 & 5 & 4.55 & 1.99 & 287 & 5 & 1.74 & 0.77 & 2.81 & 2.14 & 1.313 \\
\hline & $90 \sim 95$ & 4 & 0 & 0 & 0 & 18 & 0 & 0 & 0 & 0 & 0 & c \\
\hline & $\mathrm{MR} / \mathrm{S}_{\mathrm{MR}}$ & \multicolumn{11}{|r|}{1.86} \\
\hline \multirow{6}{*}{$\bar{I}$} & $50 \sim 60$ & 20 & 3 & 15.00 & 7.99 & 24 & 6 & 25.00 & 8.84 & -10.00 & 11.93 & $\mid-0.838$ \\
\hline & $60 \sim 70$ & 172 & 8 & 4.65 & 1.61 & 243 & 24 & 9.88 & 1.91 & -5.23 & 2.50 & -2.092 \\
\hline & $70 \sim 80$ & 323 & 25 & 7.73 & 1.49 & 551 & 32 & 5.81 & 1.00 & 1.92 & 1.79 & 1.073 \\
\hline & $80 \sim 90$ & 103 & 2 & 1.94 & 1.36 & 270 & 4 & 1.48 & 0.74 & 0.46 & 1.54 & 0.299 \\
\hline & $90 \sim 95$ & 4 & 0 & 0 & 0 & 14 & 0 & 0 & 0 & 0 & 0 & 0 \\
\hline & $\mathrm{MR} / \mathrm{S}_{\mathrm{MR}}$ & \multicolumn{11}{|r|}{-0.622} \\
\hline
\end{tabular}


老人ホーム入居者う䨑加療の統計的研觉

\begin{tabular}{|c|c|c|c|c|c|c|c|c|c|c|c|c|}
\hline \multicolumn{2}{|c|}{ 表 8} & \multicolumn{10}{|c|}{ 男女別年代別歯別（金属冠歯/F T ）率とその差 } & $(\%)$ \\
\hline \multirow{2}{*}{ 䨑 } & \multirow{2}{*}{ 年 令 層 } & \multicolumn{4}{|c|}{ 男 } & \multicolumn{4}{|c|}{ 女 } & \multicolumn{2}{|l|}{ 男 } & 女 \\
\hline & & F T & $\begin{array}{l}\text { 金属 } \\
\text { 尊 }\end{array}$ & p $(\%)$ & Sp (\%) & F T & $\begin{array}{l}\text { 金属 } \\
\text { 尊雨 }\end{array}$ & p (\%) & $\operatorname{Sp}(\%)$ & $\mathrm{d}(\%)$ & $\mathrm{Sd}(\%)$ & $\mathrm{d} / \mathrm{Sd}$ \\
\hline \multirow{6}{*}{$\overline{2}$} & $50 \sim 60$ & 21 & 4 & 19.04 & 8.57 & 24 & 6 & 25.00 & 8.84 & -5.96 & 12.31 & -0.484 \\
\hline & $60 \sim 70$ & 163 & 7 & 4.29 & 1.59 & 218 & 26 & 11.93 & 2.20 & -7.64 & 2.71 & -2.819 \\
\hline & $70 \sim 80$ & 315 & 27 & 8.57 & 1.58 & 548 & 31 & 5.66 & 0.99 & 2.91 & 1.86 & 1.564 \\
\hline & $80 \sim 90$ & 102 & 2 & 1.96 & 1.38 & 268 & 4 & 1. 49 & 0.74 & 0.47 & 1.57 & 0.299 \\
\hline & $90 \sim 95$ & 4 & 0 & 0 & 0 & 15 & 0 & 0 & 0 & 0 & 0 & 0 \\
\hline & $\mathrm{MR} / \mathrm{S}_{\mathrm{MR}}$ & & & & & & & & & & & -0.576 \\
\hline \multirow{6}{*}{3} & $50 \sim 60$ & 20 & 5 & 25.00 & 9.68 & 23 & 4 & 17.39 & 7.90 & 7.61 & 12.49 & 0.609 \\
\hline & $60 \sim 70$ & 132 & II & 8. 33 & 2.40 & 214 & 19 & 8.88 & 1.95 & -0.55 & 3.09 & -0.177 \\
\hline & $70 \sim 80$ & 278 & 26 & 9. 35 & 1.75 & 517 & 36 & 6.96 & 1. 12 & 2. 39 & 2.08 & 1.149 \\
\hline & $80 \sim 90$ & 94 & 5 & 5.32 & 2.31 & 257 & 8 & 3. 11 & 1.09 & 2.21 & 2.56 & 0.863 \\
\hline & $90 \sim 95$ & 4 & 0 & 0 & 0 & 14 & 0 & 0 & 0 & 0 & 0 & 0 \\
\hline & $\mathrm{MR} / \mathrm{S}_{\mathrm{MR}}$ & & & & & & & & & & & 0.978 \\
\hline \multirow{6}{*}{4} & $50 \sim 60$ & 1 & 3 & 13.04 & 7.02 & 27 & 7 & 25.93 & 8.44 & -12.89 & 10.92 & -1.180 \\
\hline & $60 \sim 70$ & 172 & 20 & 11.63 & 2.44 & 239 & 26 & 10.88 & 2.01 & 0.75 & 3.17 & 0.237 \\
\hline & $70 \sim 80$ & 317 & 25 & 7.88 & 1.51 & 556 & 40 & 7.19 & 1.10 & 0.69 & 1.83 & 0.377 \\
\hline & $80 \sim 90$ & 104 & 10 & 9.62 & 2.89 & 255 & 13 & 5. 10 & 1.37 & 3. 52 & 3.20 & 1.100 \\
\hline & $90 \sim 95$ & 5 & 0 & 0 & 0 & 15 & 0 & 0 & 0 & 0 & 0 & o \\
\hline & $\mathrm{MR} / \mathrm{S}_{\mathrm{MR}}$ & & & & & & & & & & & 0.214 \\
\hline \multirow{6}{*}{$\overline{5}$} & $50 \sim 60$ & 27 & 6 & 22.22 & 8.00 & 28 & 5 & 17.86 & 7.24 & 4.36 & 10.78 & 0.404 \\
\hline & $60 \sim 70$ & 204 & 16 & 7.84 & 1.88 & 248 & 25 & 10.08 & 1.91 & -2.24 & 2.68 & -0.838 \\
\hline & $70 \sim 80$ & 344 & 28 & 8.14 & 1.47 & 576 & 35 & 6.08 & 1.00 & 2.06 & 1.78 & 1. 157 \\
\hline & $30 \sim 90$ & 106 & 8 & 7.55 & 2.56 & 265 & 12 & 4.53 & 1.28 & 3.02 & 2.86 & 1.055 \\
\hline & $90 \sim 95$ & 4 & 0 & 0 & 0 & 15 & 0 & 0 & 0 & 0 & 0 & o \\
\hline & $\mathrm{MR} / \mathrm{S}_{\mathrm{MR}}$ & & & & & & & & & & & 1. 288 \\
\hline
\end{tabular}

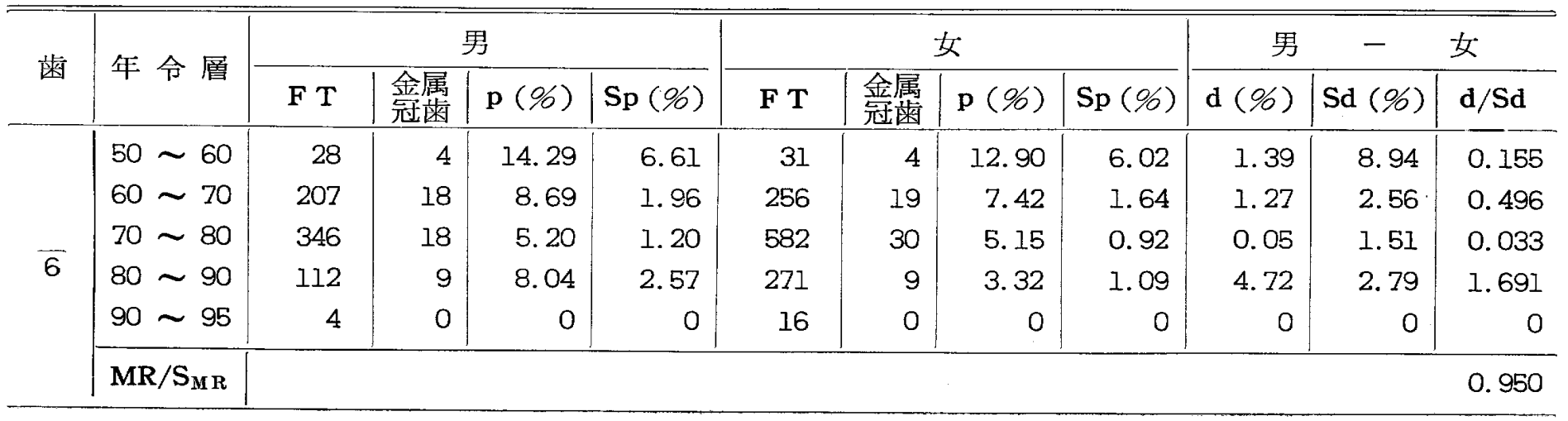




\begin{tabular}{|c|c|c|c|c|c|c|c|c|c|c|c|c|}
\hline \multirow{6}{*}{7} & $50 \sim 60$ & 25 & 5 & 20.00 & 8.00 & 28 & 5 & 17.86 & 7.24 & 2.14 & 10.79 & 0.198 \\
\hline & $60 \sim 70$ & 202 & 14 & 6.93 & 1.79 & 256 & 15 & 5. 86 & 1.46 & 1.07 & 2.31 & 0.463 \\
\hline & $70 \sim 80$ & 339 & 12 & 3.54 & 1.00 & 556 & 21 & 3. 78 & 0.81 & -0.24 & 1.29 & -0.186 \\
\hline & $80 \sim 90$ & 111 & 5 & 4.50 & 1.97 & 267 & 7 & 2.62 & 0.98 & 1.88 & 2.20 & 0.855 \\
\hline & $90 \sim 95$ & 4 & 0 & 0 & 0 & 16 & 0 & 0 & 0 & 0 & 0 & 0 \\
\hline & $\mathrm{MR} / \mathrm{S}_{\mathrm{MR}}$ & & & & & & & & & & & 0.532 \\
\hline
\end{tabular}

上 顎

中切歯：男は14.8\%〜0\%，女は29.7\%〜2.7\%.

側切霜: $8.3 \% \sim 0 \%$, 女は $18.2 \% \sim 0 \%$.

犬歯：男は $12.5 \%$ ０\%，女は10.0\%〜0\%.

第一小歯：男は15.4\%〜0\%，女は22.6\%〜0\%.

第二小臼歯: 男は19.2\%〜0\%, 女は8.4\%〜0\%.

第一大臼歯: 男は11. 1\%〜0\%, 女は7.3\% 0\%.

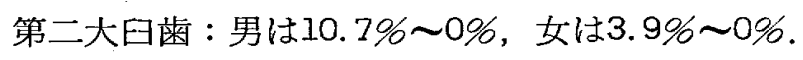

下 顎

中切歯：男は15.0\% 0\%，女は25.0\% 0\%.

側切霜：男は19.0\% 0\%, 女は $25.0 \% \sim 0 \%$.

犬歯：男は25.0\% 0\%，女は $12.4 \% \sim 0 \%$.

第一小臼苗：男は13.0\%〜0\%，女は25.9\%〜0\%.
第二小曰僯：男は22.2\%〜0\%，女は17.9\%〜0\%.

第一大臼曾：男は14.3\%\%0\%，女は12.9\%〜0\%.

第二大臼菡：男は20.0\%〜0\%，女は17.9\%〜0\%.

男女の上下顎各歯と屯増令につれて減少し, 男女間の 差はほとんどない。

3. 充填霜 $/$ F T 率 (\%)

男女別年代別の上下顎永久㐘の各歯別に，F T 数に対 する充填霜数の割合は，表10〜13の通りである.

男女之もにに上下顎の各歯ともきわめて低率である.

4. 充填崡 $/ \mathrm{DMFT}$ 率 (\%)

男女別年代別上下顎永久雪の各歯別に，DMF T 数に 対する充填蒾数の割合は, 表14〜17の通りである.

男女とも5\%以下できわぬて低率である，男女間の 表10 男女別年代別歯別（充填歯/F T ）率とその差

(\%)

\begin{tabular}{|c|c|c|c|c|c|c|c|c|c|c|c|c|}
\hline \multirow{2}{*}{ 歯 } & \multirow{2}{*}{ 年 令 層 } & \multicolumn{4}{|c|}{ 男 } & \multicolumn{4}{|c|}{ 女 } & \multicolumn{3}{|l|}{ 男 } \\
\hline & & F T & 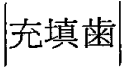 & $\mathbf{p}(\%)$ & $\mathrm{Sp}(\%)$ & F T & |充填米| & p (\%) & $\mathrm{Sp}(\%)$ & $\mathrm{d}(\%)$ & $\mathrm{Sd}(\%)$ & $\mathrm{d} / \mathrm{Sd}$ \\
\hline \multirow{6}{*}{1} & $50 \sim 60$ & 27 & 0 & 0 & 0 & 37 & 0 & 0 & 0 & 0 & 0 & 0 \\
\hline & $60 \sim 70$ & 229 & 0 & 0 & 0 & 307 & 2 & 0.65 & 0.46 & -0.65 & 0.46 & -1.413 \\
\hline & $70 \sim 80$ & 371 & 4 & 1.08 & 0.54 & 647 & 6 & 0.93 & 0.38 & 0.15 & 0.66 & 0.227 \\
\hline & $80 \sim 90$ & 114 & 3 & 2.63 & 1.50 & 294 & 2 & 0.68 & 0.48 & 1.95 & 1.58 & 1.234 \\
\hline & $90 \sim 95$ & 2 & 0 & 0 & 0 & 18 & 0 & 0 & 0 & 0 & 0 & 0 \\
\hline & $\mathrm{MR} / \mathrm{S}_{\mathrm{MR}}$ & \multicolumn{11}{|r|}{0.091} \\
\hline \multirow{6}{*}{2} & $50 \sim 60$ & 24 & 0 & 0 & 0 & 33 & 0 & 0 & 0 & 0 & 0 & 0 \\
\hline & $60 \sim 70$ & 227 & 2 & 0.88 & 0.62 & 288 & 1 & 0.35 & 0.35 & 0.53 & 0.71 & 0.746 \\
\hline & $70 \sim 80$ & 363 & 2 & 0.55 & 0.93 & 648 & 4 & 0.62 & 0.31 & -0.07 & 0.98 & -0.071 \\
\hline & $80 \sim 90$ & 110 & 0 & 0 & 0 & 287 & 1 & 0.35 & 0.35 & -0.35 & 0.35 & -1.000 \\
\hline & $90 \sim 95$ & 2 & 0 & 0 & 0 & 16 & 0 & 0 & 0 & 0 & 0 & 0 \\
\hline & $\mathrm{MR} / \mathrm{S}_{\mathrm{MR}}$ & \multicolumn{11}{|r|}{-0.130} \\
\hline \multirow{6}{*}{3} & $50 \sim 60$ & 24 & 0 & 0 & 0 & 30 & 1 & 3. 33 & 3. 28 & -3.33 & 3.28 & -1.015 \\
\hline & $60 \sim 70$ & 220 & 4 & 1.82 & 2.85 & 270 & 3 & 1.11 & 0.64 & 0.71 & 2.92 & 0.243 \\
\hline & $70 \sim 80$ & 343 & 6 & 1.75 & 0.71 & 611 & 6 & 0.98 & 0.40 & 0.77 & 0.82 & 0.939 \\
\hline & $80 \sim 90$ & 104 & 1 & 0.96 & 0.96 & 272 & 1 & 0.37 & 0.37 & 0.59 & 1.03 & 0.573 \\
\hline & $90 \sim 95$ & 3 & 0 & 0 & 0 & 16 & 0 & 0 & 0 & 0 & 0 & 0 \\
\hline & $\mathrm{MR} / \mathrm{S}_{\mathrm{MR}}$ & \multicolumn{11}{|r|}{0.296} \\
\hline
\end{tabular}




4 \begin{tabular}{|r|r|r|r|r|r|r|r|r|r|r|r}
$50 \sim 60$ & 26 & 0 & 0 & 0 & 31 & 0 & 0 & 0 & 0 & 0 & 0 \\
$60 \sim 70$ & 221 & 2 & 0.90 & 0.64 & 273 & 1 & 0.37 & 0.37 & 0.53 & 0.74 & 0.716 \\
$70 \sim 80$ & 357 & 4 & 1.12 & 0.56 & 630 & 3 & 0.48 & 0.87 & 0.64 & 1.03 & 0.621 \\
$80 \sim 90$ & 106 & 1 & 0.94 & 0.94 & 289 & 1 & 0.35 & 0.35 & 0.59 & 1.03 & 0.573 \\
$90 \sim 95$ & 3 & 0 & 0 & 0 & 18 & 0 & 0 & 0 & 0 & 0 & 0 \\
\hline MR/S & &
\end{tabular}

表11

男女別年代別䨑別（充填歯/F T) 率とその差

(\%)

\begin{tabular}{|c|c|c|c|c|c|c|c|c|c|c|c|c|}
\hline \multirow{2}{*}{ 雪 } & \multirow{2}{*}{ 年 令 層 } & \multicolumn{4}{|c|}{ 男 } & \multicolumn{4}{|c|}{ 女 } & \multicolumn{3}{|l|}{ 男 } \\
\hline & & $F T$ & 充填歯 & $\mathrm{p}(\%)$ & $\mathrm{Sp}(\%)$ & F T & |充填歯| & $\mathrm{p}(\%)$ & $\mathrm{Sp}(\%)$ & $\mathrm{d}(\%)$ & $\mathrm{Sd}(\%)$ & $\mathrm{d} / \mathrm{Sd}$ \\
\hline \multirow{6}{*}{$\underline{5}$} & $50 \sim 60$ & 26 & 0 & 0 & 0 & 27 & 0 & 0 & 0 & 0 & 0 & 0 \\
\hline & $60 \sim 70$ & 233 & 0 & 0 & 0 & 273 & 1 & 0.37 & 0.37 & -0.37 & 0.37 & -1.000 \\
\hline & $70 \sim 80$ & 353 & 4 & 1.13 & 0.56 & 638 & 1 & 0.16 & 0.16 & 0.97 & 0.58 & 1.689 \\
\hline & $80 \sim 90$ & 109 & 1 & 0.92 & 0.92 & 290 & 2 & 0.69 & 0. 49 & 0.23 & 1.03 & 0.223 \\
\hline & $90 \sim 95$ & 4 & 0 & 0 & 0 & 18 & 0 & 0 & 0 & 0 & 0 & 0 \\
\hline & $\mathrm{MR} / \mathrm{S}_{\mathrm{MR}}$ & \multicolumn{11}{|r|}{0.364} \\
\hline \multirow{6}{*}{6} & $50 \sim 60$ & 27 & 0 & 0 & 0 & 26 & 0 & 0 & 0 & 0 & 0 & 0 \\
\hline & $60 \sim 70$ & 241 & 1 & 0.42 & 0.42 & 261 & 3 & 1.15 & 2.09 & 0.73 & 2. 13 & 0.343 \\
\hline & $70 \sim 80$ & 368 & 2 & 0.54 & 0.38 & 632 & 1 & 0.16 & 0.16 & 0.38 & 0.41 & 0.926 \\
\hline & $80 \sim 90$ & 109 & 0 & 0 & 0 & 290 & 1 & 0.34 & 0.34 & -0.34 & 0.34 & -1.000 \\
\hline & $90 \sim 95$ & 4 & 0 & 0 & 0 & 18 & 0 & 0 & 0 & 0 & 0 & 0 \\
\hline & $\mathrm{MR} / \mathrm{S}_{\mathrm{MR}}$ & \multicolumn{11}{|r|}{0.108} \\
\hline \multirow{6}{*}{ 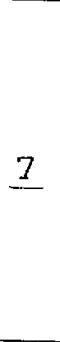 } & $50 \sim 60$ & 28 & 1 & 3.57 & 3.51 & 26 & 1 & 3.85 & 3.77 & -0.28 & 5.51 & -0.054 \\
\hline & $60 \sim 70$ & 227 & 2 & 0.88 & 0.62 & 268 & 1 & 0.37 & 0.37 & 0.51 & 0.72 & 0.708 \\
\hline & $70 \sim 80$ & 362 & 4 & 1.10 & 0.55 & 622 & 5 & 0.80 & 0.36 & 0.30 & 0.66 & 0.455 \\
\hline & $80 \sim 90$ & 110 & 0 & 0 & 0 & 287 & 1 & 0.35 & 0.35 & -0.35 & 0.35 & -1.000 \\
\hline & $90 \sim 95$ & 4 & 0 & 0 & 0 & 18 & 0 & 0 & 0 & 0 & 0 & 0 \\
\hline & $\mathrm{MR} / \mathrm{S}_{\mathrm{MR}}$ & \multicolumn{11}{|r|}{0.044} \\
\hline \multirow{6}{*}{$\bar{I}$} & $50 \sim 60$ & 20 & 0 & 0 & 0 & 24 & 0 & 0 & 0 & 0 & 0 & 0 \\
\hline & $60 \sim 70$ & 172 & 0 & 0 & 0 & 243 & 0 & 0 & 0 & 0 & 0 & 0 \\
\hline & $70 \sim 80$ & 323 & 0 & 0 & 0 & 551 & 0 & 0 & 0 & 0 & 0 & 0 \\
\hline & $80 \sim 90$ & 103 & 0 & 0 & 0 & 270 & 0 & 0 & o & 0 & 0 & 0 \\
\hline & $90 \sim 95$ & 4 & 0 & 0 & 0 & 14 & 0 & 0 & o & 0 & 0 & 0 \\
\hline & $\mathrm{MR} / \mathrm{S}_{\mathbf{M R}}$ & & & & & & & & & & & 0 \\
\hline
\end{tabular}




\begin{tabular}{|c|c|c|c|c|c|c|c|c|c|c|c|c|}
\hline \multirow{2}{*}{ 歯 } & \multirow{2}{*}{ 年 令 層 } & \multicolumn{4}{|c|}{ 男 } & \multicolumn{4}{|c|}{ 女 } & \multicolumn{2}{|l|}{ 男 } & \multirow{2}{*}{$\frac{\text { 女 }}{d / S d}$} \\
\hline & & F T & 充填曾 & $\mathrm{p}(\%)$ & $\mathrm{Sp}(\%)$ & F T & 充填柬 & $\mathrm{p}(\%)$ & $\operatorname{Sp}(\%)$ & $\mathrm{d}(\%)$ & Sd $(\%)$ & \\
\hline \multirow{6}{*}{$\overline{2}$} & $50 \sim 60$ & 21 & 0 & 0 & 0 & 24 & 1 & 4.17 & 4.08 & -4.17 & 4.08 & $\mid-1.022$ \\
\hline & $60 \sim 70$ & 163 & 1 & 0.61 & 0.61 & 218 & 1 & 0.46 & 0.46 & 0.15 & 0.77 & 0. 195 \\
\hline & $70 \sim 80$ & 315 & 3 & 0.95 & 0.54 & 548 & 0 & 0 & 0 & 0.95 & 0.54 & 1.759 \\
\hline & $80 \sim 90$ & 102 & 0 & 0 & 0 & 268 & 0 & 0 & 0 & 0 & 0 & 0 \\
\hline & $90 \sim 95$ & 4 & 0 & 0 & 0 & 15 & 0 & 0 & 0 & 0 & 0 & 0 \\
\hline & $\mathrm{MR} / \mathrm{S}_{\mathrm{MR}}$ & & & & & & & & & & & 0.372 \\
\hline \multirow{6}{*}{3} & $50 \sim 60$ & 20 & 0 & 0 & 0 & 23 & 1 & 4.35 & 4.25 & -4.35 & 4. 25 & -1.024 \\
\hline & $60 \sim 70$ & 132 & 5 & 3.78 & 1.66 & 214 & 1 & 0.47 & 0.47 & 3. 31 & 1.72 & 1.924 \\
\hline & $70 \sim 80$ & 278 & 6 & 2.15 & 0.87 & 517 & 6 & 1.16 & 0.47 & 0.99 & 0.99 & 1.000 \\
\hline & $80 \sim 90$ & 94 & 1 & 1.06 & 1.06 & 257 & 2 & 0.79 & 0.55 & 0.27 & 1.19 & 0. 227 \\
\hline & $90 \sim 95$ & 4 & 1 & 25.00 & 21.65 & 14 & 0 & 0 & 0 & 25.00 & 21.64 & 1. 155 \\
\hline & $\mathrm{MR} / \mathrm{S}_{\mathrm{MR}}$ & & & & & & & & & & & 1.312 \\
\hline \multirow{6}{*}{$\underline{4}$} & $50 \sim 60$ & 23 & 1 & 4.35 & 4.25 & 27 & 1 & 3. 70 & 3.63 & 0.65 & 5. 59 & 0.116 \\
\hline & $60 \sim 70$ & 172 & 2 & 1. 16 & 0.82 & 239 & 3 & 1.26 & 0.72 & -0.09 & 1.09 & -0.083 \\
\hline & $70 \sim 80$ & 317 & 4 & 1.26 & 0.63 & 556 & 3 & 0.54 & 0.31 & 0.72 & 0.70 & 1.029 \\
\hline & $80 \sim 90$ & 104 & 0 & 0 & 0 & 255 & 1 & 0.39 & 0.39 & -0.39 & 0.39 & -1.000 \\
\hline & $90 \sim 95$ & 5 & 1 & 20.00 & 17.88 & 15 & 0 & 0 & 0 & 20.00 & 17.86 & 1.119 \\
\hline & $\mathrm{MR} / \mathrm{S}_{\mathrm{M} \mathrm{R}}$ & & & & & & & & & & & 0.014 \\
\hline \multirow{6}{*}{5} & $50 \sim 60$ & 27 & 0 & 0 & 0 & 28 & 0 & 0 & 0 & 0 & 0 & 0 \\
\hline & $60 \sim 70$ & 204 & 4 & 1.96 & 0.97 & 248 & 3 & 1.21 & 0.69 & 0.75 & 1.19 & 0.630 \\
\hline & $70 \sim 80$ & 344 & 4 & 1.16 & 0.58 & 576 & 3 & 0.52 & 0.30 & 0.64 & 0.65 & 0.985 \\
\hline & $80 \sim 90$ & 106 & 0 & 0 & 0 & 265 & 0 & 0 & 0 & 0 & 0 & 0 \\
\hline & $90 \sim 95$ & 4 & 0 & 0 & 0 & 15 & 0 & 0 & 0 & 0 & 0 & 0 \\
\hline & $\mathrm{MR} / \mathrm{S}_{\mathrm{MR}}$ & \multicolumn{11}{|r|}{0.646} \\
\hline
\end{tabular}

\begin{tabular}{|c|c|c|c|c|c|c|c|c|c|c|c|c|}
\hline \multirow{2}{*}{ 歯 } & \multirow{2}{*}{ 年 令 層 } & \multicolumn{4}{|c|}{ 男 } & \multicolumn{4}{|c|}{ 女 } & \multicolumn{2}{|l|}{ 男 } & \multirow{2}{*}{$\frac{\text { 女 }}{d / S d}$} \\
\hline & & F T & '充填苗 & $\mathrm{p}(\%)$ & $\mathrm{Sp}(\%)$ & F T & 充填雬 & p (\%) & $\mathrm{Sp}(\%)$ & $\mathrm{d}(\%)$ & Sd (\%) & \\
\hline \multirow{6}{*}{$\overline{6}$} & $50 \sim 60$ & 28 & 0 & 0 & 0 & 31 & 3 & 9.68 & 5.32 & -9.68 & 5.32 & -1.819 \\
\hline & $60 \sim 70$ & 207 & 3 & 1.45 & 0.84 & 256 & 7 & 2.73 & 1.02 & -1.28 & 1.32 & -0.969 \\
\hline & $70 \sim 80$ & 346 & 6 & 1.73 & 0.70 & 582 & 4 & 0.69 & 0.34 & 1.04 & 0.78 & 1. 333 \\
\hline & $80 \sim 90$ & 112 & 0 & 0 & 0 & 271 & 1 & 0.37 & 0.37 & -0.37 & 0.37 & -1.000 \\
\hline & $90 \sim 95$ & 4 & 0 & 0 & 0 & 16 & 0 & 0 & 0 & 0 & 0 & 0 \\
\hline & $\mathrm{MR} / \mathrm{S}_{\mathrm{MR}}$ & \multicolumn{11}{|r|}{-0.982} \\
\hline
\end{tabular}




$\overline{7} \quad$\begin{tabular}{r|r|r|r|r|r|r|r|r|r|r|r}
$50 \sim 60$ & 25 & 0 & 0 & 0 & 28 & 2 & 7.14 & 4.86 & -7.14 & 4.89 & -1.460 \\
$60 \sim 70$ & 202 & 6 & 2.97 & 1.19 & 256 & 4 & 1.56 & 0.77 & 1.41 & 1.42 & 0.992 \\
$70 \sim 80$ & 339 & 4 & 1.18 & 0.59 & 556 & 5 & 0.90 & 0.40 & 0.28 & 0.71 & 0.394 \\
$80 \sim 90$ & 111 & 1 & 0.90 & 0.90 & 267 & 1 & 0.37 & 0.37 & 0.53 & 0.97 & 0.546 \\
$90 \sim 95$ & 4 & 0 & 0 & 0 & 16 & 0 & 0 & 0 & 0 & 0 & 0 \\
\hline $\mathrm{MR} / \mathrm{S}_{\mathrm{YIR}}$ & &
\end{tabular}

\begin{tabular}{|c|c|c|c|c|c|c|c|c|c|c|c|c|}
\hline \multirow{2}{*}{ 歯 } & \multirow{2}{*}{ 年 令 層 } & \multicolumn{4}{|c|}{ 男 } & \multicolumn{4}{|c|}{ 女 } & \multicolumn{3}{|l|}{ 男 } \\
\hline & & DMFT & 充填歯 & $\mathrm{p}(\%)$ & $\mathrm{Sp}(\%)$ & DMFT & 充填蒾| & $\mathrm{p}(\%)$ & $|\mathrm{Sp}(\mathscr{\%})|$ & $\mathrm{d}(\%)$ & $\mathrm{Sd}(\mathscr{\%})$ & $\mathrm{d} / \mathrm{Sd}$ \\
\hline \multirow{6}{*}{1} & $50 \sim 60$ & 48 & 0 & 0 & 0 & 64 & 0 & 0 & 0 & 0 & 0 & 0 \\
\hline & $60 \sim 70$ & 410 & 0 & 0 & 0 & 510 & 2 & c. 39 & 0.28 & -0.39 & 0.28 & -1.392 \\
\hline & $70 \sim 80$ & 671 & 4 & 0.59 & 0.30 & 1004 & 6 & 0.60 & 0.24 & -0.01 & 0.38 & -0.026 \\
\hline & $80 \sim 90$ & 224 & 3 & 1. 34 & 0.77 & 513 & 2 & 0.39 & 0.15 & 0.95 & 0.79 & 1.202 \\
\hline & $90 \sim 95$ & 14 & 0 & 0 & 0 & 32 & 0 & 0 & 0 & 0 & 0 & 0 \\
\hline & $\mathrm{MR} / \mathrm{S}_{\mathrm{MR}}$ & & & & & & & & & & 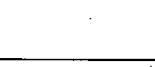 & -0.086 \\
\hline \multirow{6}{*}{$\underline{2}$} & $50 \sim 60$ & 47 & 0 & 0 & 0 & 62 & 0 & 0 & 0 & 0 & 0 & 0 \\
\hline & $60 \sim 70$ & 418 & 2 & 0.47 & 0. 32 & 488 & 1 & 0.20 & 0.20 & 0.27 & 0.38 & 0.711 \\
\hline & $70 \sim 80$ & 680 & 2 & 0.29 & 0.21 & 1004 & 4 & 0.40 & 0.20 & -0.11 & 0.29 & -0.379 \\
\hline & $80 \sim 90$ & 224 & 0 & 0 & 0 & 502 & 1 & 0.20 & 0.20 & -0.20 & 0.20 & -1.000 \\
\hline & $90 \sim 95$ & 14 & 0 & 0 & 0 & 29 & 0 & 0 & 0 & 0 & 0 & 0 \\
\hline & $\mathrm{MR} / \mathrm{S}_{\mathrm{MR}}$ & & & & & & & & & & & -0.266 \\
\hline \multirow{6}{*}{ 3} & $50 \sim 60$ & 43 & 0 & 0 & 0 & 52 & 1 & 1.92 & 1.90 & -1.92 & 1.90 & -1.101 \\
\hline & $60 \sim 70$ & 389 & 4 & 1.02 & 0.51 & 468 & 3 & 0.64 & 0.37 & 0.38 & 0.63 & 0.603 \\
\hline & $70 \sim 80$ & 646 & 6 & 0.93 & 0.38 & 965 & 6 & 0.62 & 0.25 & 0.31 & 0.45 & 0.688 \\
\hline & $80 \sim 90$ & 218 & 1 & 0.45 & 0.45 & 497 & 1 & 0.20 & 0.20 & 0.25 & 0.49 & 0.510 \\
\hline & $90 \sim 95$ & 14 & 0 & 0 & 0 & 31 & 0 & 0 & 0 & 0 & 0 & 0 \\
\hline & $\mathrm{MR} / \mathrm{S}_{\mathrm{MR}}$ & & & & & & & & & & & 0.316 \\
\hline \multirow{6}{*}{4} & $50 \sim 60$ & 47 & 0 & 0 & 0 & 55 & 0 & 0 & 0 & 0 & 0 & 0 \\
\hline & $60 \sim 70$ & 429 & 2 & 0.47 & 0.33 & 497 & 1 & 0.20 & 0.20 & 0.27 & 0.38 & 0.711 \\
\hline & $70 \sim 80$ & 699 & 4 & 0.57 & 0.29 & 1016 & 3 & 0.30 & 0.17 & 0.27 & 0.34 & 0.794 \\
\hline & $80 \sim 90$ & 230 & 1 & 0.43 & 0.43 & 515 & 1 & 0.19 & o. 19 & 0.24 & 0.47 & 0.511 \\
\hline & $90 \sim 95$ & 16 & 0 & 0 & 0 & 29 & 0 & 0 & 0 & 0 & 0 & 0 \\
\hline & $\mathrm{MR} / \mathrm{S}_{\mathrm{MR}}$ & & & & & & & & & & & 0.806 \\
\hline
\end{tabular}




\begin{tabular}{|c|c|c|c|c|c|c|c|c|c|c|c|c|}
\hline \multirow{2}{*}{ 雨 } & \multirow{2}{*}{ 年 令 層 } & \multicolumn{4}{|c|}{ 男 } & \multicolumn{4}{|c|}{ 女 } & \multicolumn{2}{|l|}{ 男 } & 女 \\
\hline & & DMFT & 充填荬 & $\mathrm{p}(\%)$ & $\mathrm{Sp}(\%)$ & DMFT & 充填歯 & $\mathrm{p}(\%)$ & Sp (\%) & $\mathrm{d}(\%)$ & $\operatorname{Sd}(\%)$ & $\mathrm{d} / \mathrm{Sd}$ \\
\hline \multirow{6}{*}{5} & $50 \sim 60$ & 51 & 0 & 0 & 0 & 61 & 0 & 0 & 0 & 0 & 0 & 0 \\
\hline & $60 \sim 70$ & 441 & 4 & 0 & 0 & 500 & 1 & 0.20 & 0.20 & -0.20 & 0.20 & -1.000 \\
\hline & $70 \sim 80$ & 701 & 1 & 0.57 & 0.29 & 1010 & 1 & 0.10 & 0.10 & 0.47 & 0.31 & 1.516 \\
\hline & $80 \sim 90$ & 231 & 0 & 0.43 & 0.43 & 517 & 2 & 0.39 & 0.28 & 0.04 & 0.51 & 0.078 \\
\hline & $90 \sim 95$ & 15 & 0 & 0 & 0 & 30 & 0 & 0 & 0 & 0 & 0 & 0 \\
\hline & $\mathrm{MR} / \mathrm{S}_{\mathrm{MR}}$ & ، & ; & & & & & & & & & 0.238 \\
\hline \multirow{6}{*}{$\underline{6}$} & $50 \sim 60$ & 55 & 0 & 0 & 0 & 61 & 0 & 0 & 0 & 0 & 0 & 0 \\
\hline & $60 \sim 70$ & 459 & 1 & 0.22 & 0.22 & 531 & 3 & 0.56 & 0.32 & -0.34 & 0.39 & -0.872 \\
\hline & $70 \sim 80$ & 720 & 2 & 0.28 & 0.20 & 1041 & 1 & 0.10 & 0.10 & 0.18 & 0.22 & 0.818 \\
\hline & $80 \sim 90$ & 238 & 0 & 0 & 0 & 523 & 1 & 0.19 & 0.19 & -0.19 & 0.19 & -1.000 \\
\hline & $90 \sim 95$ & 16 & 0 & 0 & 0 & 32 & 0 & 0 & 0 & 0 & 0 & 0 \\
\hline & $\mathrm{MR} / \mathrm{S}_{\mathrm{MR}}$ & & & & & & & & & & & -0.422 \\
\hline \multirow{6}{*}{7} & $50 \sim 60$ & 54 & 1 & 1.85 & 1.83 & 71 & 1 & 1.41 & 2.31 & 0.44 & 2.31 & 0.190 \\
\hline & $60 \sim 70$ & 466 & 2 & 0.43 & 0.30 & 520 & 1 & 0.19 & 0.19 & 0.24 & 0.35 & 0.686 \\
\hline & $70 \sim 80$ & 722 & 4 & 0.55 & 0.27 & 1050 & 5 & 0.48 & 0.22 & 0.07 & 0.35 & 0.200 \\
\hline & $80 \sim 90$ & 230 & 0 & 0 & 0 & 529 & 1 & 0.19 & 0.19 & -0.19 & 0.19 & -1.00 \\
\hline & $90 \sim 95$ & 16 & 0 & 0 & 0 & 32 & 0 & 0 & 0 & 0 & 0 & 0 \\
\hline & $\mathrm{MR} / \mathrm{S}_{\mathrm{MR}}$ & & & & & & & & & & & 0.010 \\
\hline \multirow{6}{*}{$I$} & $50 \sim 60$ & 33 & 0 & 0 & 0 & 38 & 0 & 0 & 0 & 0 & 0 & 0 \\
\hline & $60 \sim 70$ & 328 & 0 & 0 & 0 & 401 & 0 & 0 & 0 & 0 & 0 & 0 \\
\hline & $70 \sim 80$ & 600 & 0 & 0 & 0 & 867 & 0 & 0 & 0 & 0 & 0 & 0 \\
\hline & $80 \sim 90$ & 201 & 0 & 0 & 0 & 475 & 0 & 0 & 0 & 0 & 0 & 0 \\
\hline & $90 \sim 95$ & 15 & 0 & 0 & 0 & 28 & 0 & 0 & 0 & 0 & 0 & 0 \\
\hline & $\mathrm{MR} / \mathrm{S}_{\mathrm{MR}}$ & & & & & & & & & & & 0 \\
\hline
\end{tabular}

\begin{tabular}{|c|c|c|c|c|c|c|c|c|c|c|c|c|}
\hline \multirow{2}{*}{ 蒾 } & \multirow{2}{*}{ 年 令 層 } & \multicolumn{4}{|c|}{ 男 } & \multicolumn{4}{|c|}{ 女 } & \multicolumn{2}{|c|}{ 男 - } & 女 \\
\hline & & DMFT & |充填菡 & $\mathrm{p}(\%)$ & $\operatorname{Sp}(\%)$ & DMFT & |充填歯| & p (\%) & Sp (\%) & $\mathrm{d}(\%)$ & Sd (\%) & $d / S d$ \\
\hline \multirow{6}{*}{$\overline{2}$} & $50 \sim 60$ & 36 & 0 & 0 & 0 & 40 & 1 & 2.50 & 2.46 & -2.50 & 2.46 & -1.016 \\
\hline & $60 \sim 70$ & 311 & 1 & 0.32 & 0.32 & 384 & 1 & 0.26 & 0.26 & 0.06 & 0.41 & 0.146 \\
\hline & $70 \sim 80$ & 573 & 3 & 0.52 & 0.30 & 846 & 0 & 0 & 0 & 0.52 & 0.30 & 1.733 \\
\hline & $80 \sim 90$ & 192 & 0 & 0 & 0 & 459 & 0 & 0 & 0 & 0 & 0 & 0 \\
\hline & $90 \sim 95$ & 15 & 0 & 0 & 0 & 28 & 0 & 0 & 0 & 0 & 0 & 0 \\
\hline & $\mathrm{MR} / \mathrm{S}_{\mathrm{MR}}$ & \multicolumn{11}{|r|}{0.344} \\
\hline
\end{tabular}




\begin{tabular}{|c|c|c|c|c|c|c|c|c|c|c|c|c|}
\hline \multirow{6}{*}{3} & $50 \sim 60$ & 36 & 0 & 0 & 0 & 36 & $I$ & 2.78 & 2.74 & -2.78 & 2.74 & -1.015 \\
\hline & $60 \sim 70$ & 276 & 5 & 1.81 & 2.54 & 384 & 1 & 0.26 & 0.26 & 1.55 & 2.55 & 0.607 \\
\hline & $70 \sim 80$ & 524 & 6 & 1.15 & 0.46 & 822 & 6 & 0.73 & 0.30 & 0.42 & 0.55 & 0.763 \\
\hline & $80 \sim 90$ & 184 & 1 & 0.54 & 0.54 & 444 & 2 & 0.45 & 0.32 & 0.09 & 0.63 & O. 143 \\
\hline & $90 \sim 95$ & 13 & 1 & 7.69 & 7.39 & 27 & 0 & 0 & 0 & 7.69 & 7.39 & 1.041 \\
\hline & $\mathrm{MR} / \mathrm{S}_{\mathrm{MR}}$ & & & & & & & & & & & 0.616 \\
\hline \multirow{6}{*}{$\overline{4}$} & $50 \sim 60$ & 44 & 1 & 2.27 & 2.25 & 49 & 1 & 2.04 & 2.02 & 0.23 & 3.02 & 0.076 \\
\hline & $60 \sim 70$ & 340 & 2 & 0.59 & 0.42 & 427 & 3 & 0.70 & 0.40 & -0.11 & 0.58 & -0.189 \\
\hline & $70 \sim 80$ & 616 & 4 & 0.65 & 0.33 & 912 & 3 & 0.33 & 0.19 & 0.22 & 0.38 & 0.579 \\
\hline & $80 \sim 90$ & 201 & 0 & 0 & 0 & 482 & 1 & 0.21 & 0.21 & -0.21 & 0.21 & -1.000 \\
\hline & $90 \sim 95$ & 14 & 1 & 7.14 & 6.88 & 27 & 0 & 0 & 0 & 7.14 & 6.88 & 1.038 \\
\hline & $\mathrm{MR} / \mathrm{S}_{\mathrm{MR}}$ & \multicolumn{11}{|r|}{0.202} \\
\hline \multirow{6}{*}{5} & $50 \sim 60$ & 48 & 0 & 0 & 0 & 57 & 0 & 0 & 0 & 0 & 0 & 0 \\
\hline & $60 \sim 70$ & 389 & 4 & 1.03 & 0.51 & 472 & 3 & 0.64 & 0.37 & 0.39 & 0.63 & 0.619 \\
\hline & $70 \sim 80$ & 679 & 4 & 0.59 & 0.29 & 1005 & 3 & 0.30 & 0.17 & 0.29 & 0.34 & 0.853 \\
\hline & $80 \sim 90$ & 217 & 0 & 0 & 0 & 507 & 0 & 0 & 0 & 0 & 0 & 0 \\
\hline & $90 \sim 95$ & 14 & 0 & 0 & 0 & 29 & 0 & 0 & o & 0 & 0 & 0 \\
\hline & $\mathrm{MR} / \mathrm{S}_{\mathrm{MR}}$ & & & & & & & & & & & 0.588 \\
\hline
\end{tabular}

\begin{tabular}{|c|c|c|c|c|c|c|c|c|c|c|c|c|}
\hline \multirow{2}{*}{ 崡 } & \multirow{2}{*}{ 年 令 層 } & \multicolumn{4}{|c|}{ 男 } & \multicolumn{4}{|c|}{ 女 } & \multicolumn{2}{|c|}{ 男 } & 女 \\
\hline & & DMFT & 充填歯 & p (\%) & $\mathrm{Sp}(\%)$ & DMFT & 充填歯 & p (\%) & $\mathrm{Sp}(\%)$ & $\mathrm{d}(\%)$ & $\mathrm{Sd}(\%)$ & $\mathrm{d} / \mathrm{Sd}$ \\
\hline \multirow{6}{*}{$\overline{6}$} & $50 \sim 60$ & 52 & 0 & 0 & 0 & 66 & 3 & 4.55 & 2.56 & -4.55 & 2.56 & -1.777 \\
\hline & $60 \sim 70$ & 455 & 3 & 0.66 & 0.38 & 548 & 7 & 1.28 & 0.48 & -0.62 & 0.61 & -1.016 \\
\hline & $70 \sim 80$ & 751 & 6 & 0.80 & 0.32 & 1056 & 4 & 0.38 & 0.19 & 0.42 & 0.37 & 1.135 \\
\hline & $80 \sim 90$ & 236 & 0 & 0 & 0 & 533 & 1 & 0.19 & 0.19 & -0.19 & 0.19 & -1.000 \\
\hline & $90 \sim 95$ & 15 & 0 & 0 & 0 & 32 & 0 & 0 & 0 & 0 & 0 & 0 \\
\hline & $\mathrm{MR} / \mathrm{S}_{\mathrm{MR}}$ & \multicolumn{11}{|r|}{-1.064} \\
\hline \multirow{6}{*}{7} & $50 \sim 60$ & 57 & 0 & 0 & 0 & 68 & 2 & 2.94 & 2.05 & -2.90 & 2.05 & -1.415 \\
\hline & $60 \sim 70$ & 540 & 6 & 1.32 & 0.53 & 541 & 4 & 0.74 & 0.37 & 0.58 & 0.90 & 0.644 \\
\hline & $70 \sim 80$ & 755 & 4 & 0.53 & 0.26 & 1066 & 5 & 0.47 & 0.21 & 0.06 & 0.34 & 0.176 \\
\hline & $80 \sim 90$ & 237 & 1 & 0.42 & 0.42 & 533 & 1 & 0.19 & 0.19 & 0.23 & 0.46 & 0.500 \\
\hline & $90 \sim 95$ & 16 & 0 & 0 & 0 & 32 & 0 & 0 & 0 & 0 & 0 & 0 \\
\hline & $\mathrm{MR} / \mathrm{S}_{\mathrm{MR}}$ & \multicolumn{11}{|r|}{-0.038} \\
\hline
\end{tabular}

差, 増命による差などいずれも著しくなかった。

5. $\mathrm{MT} \rightarrow \mathrm{F} \mathrm{T} / \mathrm{MT}$ 率 (\%)

これはＭT数に対し，MTからFTになったものの比 率で, 各歯別に年代別の成績は，表 18〜2 1の通りであ る.

\section{上 蕷}

中切歯：男は60.5\%〜14.3\%，女は69.1\%〜53.3\%.
側切雷: 男は81.5\%〜14.3\%，女は68.3\%〜55.2\%. 犬歯：男は65.6\%〜25.0\%, 女は92.9\%〜9.5\%.

第一小臼霜：男は55.0\%〜21.4\%，女は57.1\%〜64.3 $\%$.

第二小曰霜：男は52.5\%〜26.7\%，女は55.3\%〜60.0 $\%$.

第一大臼歯：男は51.1\%〜25.0\%，女は56.8\%〜58.1 
男女別年代別歯別 $(\mathrm{MT} \rightarrow \mathrm{FT} / \mathrm{MT})$ 率之その差

\begin{tabular}{|c|c|c|c|c|c|c|c|c|c|c|c|c|}
\hline \multirow{2}{*}{ 歯 } & \multirow{2}{*}{ 年 令 層 } & \multicolumn{4}{|c|}{ 男 } & \multicolumn{4}{|c|}{ 女 } & \multicolumn{3}{|c|}{ 男 - } \\
\hline & & MT & $\left|\begin{array}{r|}\mathrm{MT} \\
\mathrm{FT}\end{array}\right|$ & $\mathrm{p}(\%)$ & $\mathrm{Sp}(\%)$ & MT & $\stackrel{\mathrm{MT} \rightarrow}{\mathrm{FT}}$ & $\mathrm{p}(\%)$ & $\mathrm{Sp}(\%)$ & $\mathrm{d}(\%)$ & $\mathrm{Sd}(\%)$ & $\mathrm{d} / \mathrm{Sd}$ \\
\hline \multirow{6}{*}{ I } & $50 \sim 60$ & 38 & 23 & 60.52 & 7.93 & 42 & 29 & 69.05 & 7.13 & -8.53 & 10.66 & -0.800 \\
\hline & $60 \sim 70$ & 344 & 213 & 61.92 & 2.62 & 443 & 275 & 62.08 & 2.31 & -0.16 & 3.50 & -0.046 \\
\hline & $70 \sim 80$ & 619 & 348 & 56.21 & 1.99 & 896 & 603 & 67.30 & 1.57 & -11.09 & 2.54 & -4.366 \\
\hline & $80 \sim 90$ & 208 & 108 & 51.92 & 3. 46 & 482 & 287 & 59.54 & 2.24 & -7.62 & 4. 12 & -1.849 \\
\hline & $90 \sim 95$ & 14 & 2 & 14.28 & 9.43 & 30 & 16 & 53.33 & 9.11 & -39.05 & 13.11 & -2.979 \\
\hline & $\mathrm{MR} / \mathrm{S}_{\mathrm{MR}}$ & & & & & & & & & & & -4.012 \\
\hline \multirow{6}{*}{2} & $50 \sim 60$ & 27 & 22 & 81.48 & 7.48 & 41 & 28 & 68.29 & 7.27 & 13.19 & 10.43 & 1.265 \\
\hline & $60 \sim 70$ & 358 & 219 & 61.17 & 2.55 & $\Delta 44$ & 271 & 61.04 & 2.32 & 0.13 & 3.47 & 0.037 \\
\hline & $70 \sim 80$ & 616 & 345 & 56.17 & 2.00 & 903 & 613 & 67.88 & 1.55 & -11.71 & 2.53 & -4.628 \\
\hline & $80 \sim 90$ & 211 & 107 & 50.71 & 3. 44 & 471 & 281 & 59.66 & 2.26 & -8.95 & 4.12 & -2.172 \\
\hline & $90 \sim 95$ & 14 & 2 & 14.28 & 9.43 & 29 & 16 & 55.17 & 9.24 & -40.89 & 13.20 & -3.097 \\
\hline & $\mathrm{MR} / \mathrm{S}_{\mathrm{MR}}$ & & & & & & & & & & & -3.452 \\
\hline \multirow{6}{*}{3} & $50 \sim 60$ & 32 & 21 & 65.62 & 8.40 & 28 & 26 & 92.86 & 4.86 & -27.24 & 9.71 & -2.805 \\
\hline & $60 \sim 70$ & 285 & 194 & 68.07 & 2.76 & 384 & 244 & 63.54 & 2.46 & 4.53 & 3.64 & 1.245 \\
\hline & $70 \sim 80$ & 532 & 315 & 59.21 & 2.13 & 823 & 577 & 70.11 & 1.59 & -10.90 & 2.66 & -4.097 \\
\hline & $80 \sim 90$ & 188 & 100 & 53.19 & 3.64 & $4 \Delta 3$ & 263 & 59.36 & 2.33 & -6.17 & 4.32 & -1.428 \\
\hline & $90 \sim 95$ & 12 & 3 & 25.00 & 12.50 & 26 & 16 & 61.54 & 9.54 & -36.54 & 15.73 & -2.323 \\
\hline & $\mathrm{MR} / \mathrm{S}_{\mathrm{MR}}$ & & & & & & & & & & & -3.762 \\
\hline \multirow{6}{*}{4} & $50 \sim 60$ & 40 & 22 & 55.00 & 7.87 & 42 & 24 & 57.14 & 7.64 & -2.14 & 10.96 & -0.195 \\
\hline & $60 \sim 70$ & 365 & 208 & 56.98 & 2.59 & 425 & 244 & 57.41 & 2.39 & -0.43 & 3.53 & -0.122 \\
\hline & $70 \sim 80$ & 616 & 342 & 55.51 & 2.00 & 897 & 591 & 65.89 & 1.58 & -10.38 & 2.55 & -4.071 \\
\hline & $80 \sim 90$ & 208 & 103 & 49.51 & 3.47 & 482 & 284 & 58.92 & 2.25 & -9.41 & 4.14 & -2.272 \\
\hline & $90 \sim 95$ & 14 & 3 & 21.42 & 10.96 & 28 & 18 & 64.29 & 9.06 & -42.87 & 14.28 & -3.000 \\
\hline & $\mathrm{MR} / \mathrm{S}_{\mathrm{MR}}$ & & & & & & & & & & & -3.864 \\
\hline
\end{tabular}

\begin{tabular}{|c|c|c|c|c|c|c|c|c|c|c|c|c|}
\hline \multirow{2}{*}{ 雬 } & \multirow{2}{*}{ 年 令 層 } & \multicolumn{4}{|c|}{ 男 } & \multicolumn{4}{|c|}{ 女 } & \multicolumn{2}{|l|}{ 男 } & 女 \\
\hline & & MT & $\begin{array}{l}\mathrm{MT} \rightarrow \overrightarrow{\mathrm{FT}} \\
\end{array}$ & p (\%) & $\mathrm{Sp}(\%)$ & MT & $\mid \begin{array}{r}\mathrm{MT} \rightarrow \overrightarrow{\mathrm{FT}} \\
\mathrm{F}\end{array}$ & p (\%) & $\mathrm{Sp}(\%)$ & $\mathrm{d}(\%)$ & $\mathrm{Sd}(\%)$ & $\mathrm{d} / \mathrm{Sd}$ \\
\hline \multirow{6}{*}{$\underline{5}$} & $50 \sim 60$ & 40 & 21 & 52.50 & 7.90 & 47 & 26 & 55.32 & 7.25 & -2.82 & 10.72 & -0.263 \\
\hline & $60 \sim 70$ & 382 & 215 & 56.28 & 2.54 & 432 & 250 & 57.87 & 2.38 & -1.59 & 3.48 & -0.457 \\
\hline & $70 \sim 80$ & 632 & 335 & 53.01 & 1.99 & 740 & 613 & 82.84 & 1.39 & -29.83 & 2.43 & -12.275 \\
\hline & $80 \sim 90$ & 218 & 105 & 48.16 & 3. 38 & 485 & 283 & 58.35 & 2.24 & -10.19 & 4.05 & -2.516 \\
\hline & $90 \sim 95$ & 15 & 4 & 26.66 & 11.41 & 30 & 18 & 60.00 & 8.94 & -33.34 & 14.49 & -2.301 \\
\hline & $\mathrm{MR} / \mathrm{S}_{\mathrm{MR}}$ & \multicolumn{11}{|r|}{-7.124} \\
\hline
\end{tabular}


老人ホーム入居者う雬加療の統計的研究

\begin{tabular}{|c|c|c|c|c|c|c|c|c|c|c|c|c|}
\hline \multirow{6}{*}{6} & $50 \sim 60$ & 45 & 23 & 51.11 & 7.45 & 44 & 25 & 56.81 & 7.47 & -5.70 & 10.55 & -0.540 \\
\hline & $60 \sim 70$ & 404 & 224 & 55.44 & 2.47 & 475 & 242 & 50.95 & 2.29 & 4.49 & 3.37 & 1.332 \\
\hline & $70 \sim 80$ & 656 & 354 & 53.96 & 1.94 & 768 & 613 & 79.82 & 1.42 & -25.86 & 2.42 & -10.685 \\
\hline & $80 \sim 90$ & 226 & 106 & 46.90 & 3. 32 & 494 & 284 & 57.49 & 2.22 & -10.59 & 4.00 & -2.647 \\
\hline & $90 \sim 95$ & 16 & 4 & 25.00 & 10.82 & 31 & 18 & 58.06 & 8.86 & -33.06 & 13.98 & -2.364 \\
\hline & $\mathrm{MR} / \mathrm{S}_{\mathrm{MR}}$ & & & & & & & & & & & -5.9 \\
\hline \multirow{6}{*}{7} & $50 \sim 60$ & 45 & 24 & 53.33 & 7.44 & 53 & 24 & 45.28 & 6.84 & 8.05 & 10.11 & 0.7 \\
\hline & $60 \sim 70$ & 420 & 214 & 50.95 & 2.44 & 477 & 259 & 54.30 & 2.29 & -3.35 & 7.26 & 0.461 \\
\hline & $70 \sim 80$ & 666 & 346 & 51.95 & 1.94 & 992 & 606 & 61.09 & 1.55 & -9.14 & 2.48 & -3.68 \\
\hline & $80 \sim 90$ & 217 & 105 & 48.38 & 3. 39 & 512 & 282 & 55.08 & 2.20 & -6.70 & 4.04 & -1.658 \\
\hline & $90 \sim 95$ & 16 & 14 & 25.00 & 10.82 & 30 & 18 & 60.00 & 8.94 & -35.00 & 14.03 & -2.495 \\
\hline & $\mathrm{MR} / \mathrm{S}_{\mathrm{MR}}$ & & & & & & & & & & & -2.632 \\
\hline \multirow{6}{*}{1} & $50 \sim 60$ & 27 & 17 & 62.96 & 9.26 & 27 & 19 & 70.37 & 8.79 & -7.41 & 12.79 & -0.579 \\
\hline & $60 \sim 70$ & 296 & 165 & 55.74 & 2.89 & 363 & 229 & 63.09 & 2.54 & -7.35 & 3.85 & -1.909 \\
\hline & $70 \sim 80$ & 564 & 311 & 55.14 & 2.09 & 798 & 523 & 65.62 & 1.69 & -10.48 & 2.69 & -3.895 \\
\hline & $80 \sim 90$ & 189 & 101 & 53.44 & 3.63 & 444 & 266 & 59.91 & 2.32 & -6.47 & 4. 31 & -1.501 \\
\hline & $90 \sim 95$ & 15 & 4 & 26.66 & 11.41 & 24 & 14 & 58.33 & 10.06 & -31.67 & 15.25 & -2.076 \\
\hline & $\mathrm{MR} / \mathrm{S}_{\mathrm{MR}}$ & \multicolumn{11}{|r|}{-3.984} \\
\hline
\end{tabular}

表20

男女別年代別歯別 $(\mathrm{MT} \rightarrow \mathrm{FT} / \mathrm{MT})$ 率之その差

(\%)

\begin{tabular}{|c|c|c|c|c|c|c|c|c|c|c|c|c|}
\hline \multirow{2}{*}{ 歯 } & \multirow{2}{*}{ 年 令 層 } & \multicolumn{4}{|c|}{ 男 } & \multicolumn{4}{|c|}{ 女 } & \multicolumn{2}{|l|}{ 男 } & 女 \\
\hline & & MT & $\mid \begin{array}{r}\mathrm{MTT} \\
\mathrm{FT}\end{array}$ & p (\%) & $\mathrm{Sp}(\%)$ & MT & 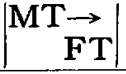 & p (\%) & $\mathrm{Sp}(\%)$ & $\mathrm{d}(\%)$ & Sd $(\%)$ & $\mathrm{d} / \mathrm{Sd}$ \\
\hline \multirow{6}{*}{$\overline{2}$} & $50 \sim 60$ & 29 & 18 & 62.06 & 9.01 & 25 & 17 & 68.00 & 9.33 & -5.94 & 12.97 & -0.458 \\
\hline & $60 \sim 70$ & 273 & 158 & 57.87 & 2.99 & 330 & 196 & 59.39 & 2.71 & -1.52 & 4.03 & -0.377 \\
\hline & $70 \sim 80$ & 515 & 298 & 57.86 & 2.18 & 774 & 524 & 67.70 & 1.68 & -9.84 & 2.76 & -3.565 \\
\hline & $80 \sim 90$ & 181 & 100 & 55.24 & 3.70 & 421 & 264 & 62.71 & 2.36 & -7.47 & 4.39 & -1.701 \\
\hline & $90 \sim 95$ & 15 & 4 & 26.66 & 11.41 & 24 & 15 & 62.50 & 9.88 & -35.84 & 15.09 & -2.544 \\
\hline & $\mathrm{MR} / \mathrm{S}_{\mathrm{MR}}$ & \multicolumn{11}{|r|}{-3.458} \\
\hline \multirow{6}{*}{3} & $50 \sim 60$ & 29 & 17 & 58.62 & 9.15 & 22 & 18 & 81.82 & 8.23 & -23.20 & 12.36 & -1.877 \\
\hline & $60 \sim 70$ & 198 & 116 & 58.58 & 1.11 & 312 & 194 & 62.18 & 2.75 & -3.60 & 2.96 & -1.216 \\
\hline & $70 \sim 80$ & 405 & 246 & 60.74 & 2.43 & 706 & 477 & 67.56 & 1.77 & -6.82 & 3. OI & -2.265 \\
\hline & $80 \sim 90$ & 155 & 88 & 56.77 & 3.98 & 379 & 248 & 65.44 & 2.44 & -8.67 & 4.67 & -1.856 \\
\hline & $90 \sim 95$ & 11 & 3 & 27.27 & 7.51 & 22 & 14 & 63.64 & 10.26 & -36.37 & 12.71 & -2.862 \\
\hline & $\mathrm{MR} / \mathrm{S}_{\mathrm{MR}}$ & \multicolumn{11}{|r|}{-4.030} \\
\hline \multirow{6}{*}{4} & $50 \sim 60$ & 36 & 19 & 52.77 & 8.32 & 29 & 19 & 65.52 & 8.83 & -12.75 & 12.13 & -1.051 \\
\hline & $60 \sim 70$ & 277 & 151 & 54.51 & 2.99 & 346 & 212 & 61.27 & 2.62 & -6.76 & 3.98 & -1.698 \\
\hline & $70 \sim 80$ & 519 & 290 & 55.87 & 2.18 & 798 & 516 & 64.66 & 1.69 & -8.79 & 2.76 & -3.185 \\
\hline & $80 \sim 90$ & 166 & 94 & 56.63 & 3.84 & 419 & 243 & 58.00 & 2.41 & -1.37 & 4.53 & -0.302 \\
\hline & $90 \sim 95$ & 13 & 4 & 30.76 & 12.77 & 26 & 15 & 57.69 & 9.69 & -26.93 & 16.03 & -1.679 \\
\hline & $\mathrm{MR} / \mathrm{S}_{\mathrm{MR}}$ & \multicolumn{11}{|r|}{-3.166} \\
\hline
\end{tabular}




\begin{tabular}{|c|c|c|c|c|c|c|c|c|c|c|c|c|}
\hline \multirow{6}{*}{5} & $50 \sim 60$ & 29 & 21 & 72.41 & 8.30 & 47 & 25 & 53. 19 & 7.28 & 19.22 & 11.04 & 1.741 \\
\hline & $60 \sim 70$ & 343 & 185 & 53.93 & 2.68 & 417 & 223 & 53.48 & 2. 44 & 0.45 & 3.63 & 0.124 \\
\hline & $70 \sim 80$ & 601 & 317 & 52.74 & 2.04 & 911 & 546 & 59.93 & 1.62 & -7.19 & 2.60 & -2.765 \\
\hline & $80 \sim 90$ & 192 & 98 & 51.04 & 3.61 & 477 & 256 & 53.67 & 2.29 & -2.63 & 4.27 & -0.616 \\
\hline & $90 \sim 95$ & 14 & 4 & 28.57 & 12.06 & 29 & 15 & 51.72 & 9.28 & -23.15 & 15.21 & -1.522 \\
\hline & $\mathrm{MR} / \mathrm{S}_{\mathrm{MR}}$ & & & & & & & & & & & -1.214 \\
\hline
\end{tabular}

\begin{tabular}{|c|c|c|c|c|c|c|c|c|c|c|c|c|}
\hline 歯 & 年 令 層 & \multicolumn{4}{|c|}{ 男 } & \multicolumn{4}{|c|}{ 女 } & \multicolumn{2}{|l|}{ 男 } & 女 \\
\hline \multirow{4}{*}{6} & $60 \sim 70$ & 396 & 188 & 47.48 & 2.51 & 503 & 237 & 4.7 .12 & 3. 12 & 0.36 & $4 . \mathrm{Ol}$ & 0.090 \\
\hline & $70 \sim 80$ & 679 & 323 & 47.57 & 1.92 & 982 & 563 & 57.33 & 0.50 & -9.76 & 1.98 & -4.929 \\
\hline & $80 \sim 90$ & 212 & 105 & 49.53 & 3.43 & 504 & 266 & 52.78 & 2.22 & -3.25 & 4.08 & -0.797 \\
\hline & $\mathrm{MR} / \mathrm{S}_{\mathrm{MR}}$ & & & & & & & & & & & -2.652 \\
\hline \multirow{4}{*}{$\overline{7}$} & $50 \sim 60$ & 47 & 20 & 42.55 & 7.25 & 54 & 21 & 38.89 & 6.64 & 3.66 & 9.83 & 0. 372 \\
\hline & $60 \sim 70$ & 413 & 184 & 44.55 & 2.44 & 505 & 239 & 47.33 & 2.22 & -2.78 & 3.30 & -0.842 \\
\hline & $70 \sim 80$ & 706 & 324 & 45.89 & 1.88 & 1015 & 539 & 53.10 & 1.57 & -7.21 & 4.00 & -2.942 \\
\hline & $\mathrm{MR} / \mathrm{S}_{\mathrm{MR}}$ & & & & & & & & & & & -2.958 \\
\hline
\end{tabular}

$\%$.

第二大田㐘：男は53.3\%〜25.0\%，女は 45.3\%〜60.0 $\%$

\section{下 顎}

中切拳：男は63.0\%〜26.7\%，女は70.4\%〜58.3\%.

側切霜：男は62.1\%〜26.7\%, 女は68.0\%〜62.5\%.

犬崡：男は58.6\%〜27.3\%，女は81.8\%〜63.6\%.

第一小曰歯：男は52.8\%〜30.8\%，女は65.5\%〜57.7
第二小罒菡：男は72.49\%〜28.6，女は53.2\%〜51.7 $\%$.

第一大曰歯：男は54.6\%〜26.7\%, 女は47.3\%〜51.6 $\%$.

第二大四歯：男は 42.6\%〜25.0\%，女は38.9\%〜53.3 $\%$.

上下顎の各歯こ660\%〜50\%以上は宦失歯の未処理㐘 である。

\begin{tabular}{|c|c|c|c|c|c|c|c|c|c|c|c|c|}
\hline \multirow[b]{2}{*}{ 歯 } & \multirow{2}{*}{ 年 令 層 } & \multicolumn{4}{|c|}{ 男 } & \multicolumn{4}{|c|}{ 女 } & \multicolumn{2}{|l|}{ 男 } & 女 \\
\hline & & T. exi, & $\underset{\mathbf{T}}{\mathrm{Al} . \mathrm{P}}$ & p (\%) & Sp (\%) & T. exi, & $\underset{\mathrm{T} .}{\mathrm{Al} . \mathrm{P}}$ & $\mathrm{p}(\%)$ & Sp (\%) & $\mathrm{d}(\%)$ & $\mathrm{Sd}(\%)$ & $\mathrm{d} / \mathrm{Sd}$ \\
\hline \multirow{6}{*}{1} & $50 \sim 60$ & 26 & 7 & 26.92 & 8.70 & 44 & 4 & 9.09 & 4. 33 & 17.83 & 5.13 & 3.475 \\
\hline & $60 \sim 70$ & 196 & 32 & 16.33 & 2.64 & 145 & 14 & 9.66 & 2.46 & 6.67 & 3.61 & 1.847 \\
\hline & $70 \sim 80$ & 185 & 34 & 18.37 & 2.85 & 224 & 35 & 15.63 & 2.43 & 2.74 & 3.75 & 0.731 \\
\hline & $80 \sim 90$ & 38 & 11 & 28.94 & 7.36 & 68 & 7 & 10.29 & 3.68 & 18.65 & 8.23 & 2.266 \\
\hline & $90 \sim 95$ & 2 & 0 & o & 0 & 0 & 0 & 0 & 0 & 0 & 0 & 0 \\
\hline & $\mathrm{MR} / \mathrm{S}_{\mathrm{MR}}$ & \multicolumn{11}{|r|}{3.328} \\
\hline
\end{tabular}




\begin{tabular}{|c|c|c|c|c|c|c|c|c|c|c|c|c|}
\hline \multirow{6}{*}{2} & $50 \sim 60$ & 27 & 3 & 11.11 & 6.05 & 38 & 3 & 7.89 & 4.37 & 3.22 & 7.47 & 0.431 \\
\hline & $60 \sim 70$ & 182 & 25 & 13.74 & 2.55 & 144 & 9 & 6.25 & 2.02 & 7.49 & 3.25 & 2. 304 \\
\hline & $70 \sim 80$ & 187 & 35 & 18.71 & 2.85 & 217 & 21 & 9.68 & 2.01 & 9.03 & 3.49 & 2. 587 \\
\hline & $80 \sim 90$ & 35 & 11 & 31.42 & 7.85 & 79 & 11 & 13.92 & 3.89 & 17.50 & 8.76 & 1.997 \\
\hline & $90 \sim 95$ & 2 & 0 & 0 & 0 & 3 & 0 & 0 & 0 & 0 & 0 & 0 \\
\hline & $\mathrm{MR} / \mathrm{S}_{\mathrm{M} \mathbf{R}}$ & & & & & & & & & & & 2. 926 \\
\hline \multirow{6}{*}{3} & $50 \sim 60$ & 32 & 3 & 9.38 & 5. 15 & 42 & 4 & 9.52 & 4.53 & -0.14 & 6.86 & -0.020 \\
\hline & $60 \sim 70$ & 255 & $4 I$ & 16.08 & 2. 30 & 204 & 28 & 13.73 & 2. 41 & 2.35 & 3.46 & 0.679 \\
\hline & $70 \sim 80$ & 261 & 51 & 19.54 & 2.46 & 297 & 49 & 16.50 & 2.15 & 3.04 & 3.27 & 0.929 \\
\hline & $80 \sim 90$ & 58 & 17 & 29.31 & 5.98 & 107 & 27 & 25.23 & 4.20 & 4.08 & 7.31 & 0.558 \\
\hline & $90 \sim 95$ & 4 & 1 & 25.00 & 21.65 & 1 & 1 & 100.00 & 0 & -75.00 & 21.62 & -3.469 \\
\hline & $\mathrm{MR} / \mathrm{S}_{\mathrm{MR}}$ & & & & & & & & & & & -0.528 \\
\hline \multirow{6}{*}{4} & $50 \sim 60$ & 24 & 2 & 8.33 & 5.64 & 38 & 2 & 5. 26 & 3.62 & 3.07 & 6.70 & 0.458 \\
\hline & $60 \sim 70$ & 175 & 25 & 14.29 & 2.64 & 161 & 17 & 10.56 & 2.42 & 3.73 & 3.58 & 1.041 \\
\hline & $70 \sim 80$ & 173 & 26 & 15.03 & 2.72 & 224 & 24 & 10.71 & 2.07 & 4. 32 & 3. 42 & 1.263 \\
\hline & $80 \sim 90$ & 38 & 10 & 26.31 & 7.15 & 68 & 7 & 10.29 & 3.68 & 16.02 & 8.04 & 1.992 \\
\hline & $90 \sim 95$ & 2 & 0 & 0 & 0 & 3 & o & 0 & 0 & 0 & 0 & 0 \\
\hline & $\mathrm{MR} / \mathrm{S}_{\mathrm{MR}}$ & \multicolumn{11}{|r|}{1.902} \\
\hline
\end{tabular}

\begin{tabular}{|c|c|c|c|c|c|c|c|c|c|c|c|c|}
\hline \multirow{2}{*}{ 歯 } & \multirow{2}{*}{ 年 令 層 } & \multicolumn{4}{|c|}{ 男 } & \multicolumn{4}{|c|}{ 女 } & \multicolumn{2}{|l|}{ 男 } & 女 \\
\hline & & Texi. & $\begin{array}{c}\text { Al. P. } \\
\text { T. }\end{array}$ & p (\%) & $\mathrm{Sp}(\%)$ & T. exi. & Al. p. & d $(\%)$ & $\operatorname{Sp}(\%)$ & $\mathrm{d}(\%)$ & $\operatorname{Sd}(\%)$ & $\mathrm{d} / \mathrm{Sd}$ \\
\hline \multirow{6}{*}{5} & $50 \sim 60$ & 24 & 3 & 12.50 & 6.75 & 33 & 4 & 12.12 & 5.68 & 0.38 & 8. 82 & 0.043 \\
\hline & $60 \sim 70$ & 158 & 19 & 12.03 & 2.59 & 156 & 16 & 10.26 & 2.43 & 1.77 & 3. 55 & 0.499 \\
\hline & $70 \sim 80$ & 131 & 27 & 20.61 & 3.53 & 180 & 43 & 23.89 & 3.18 & -3.28 & 4.85 & -0.676 \\
\hline & $80 \sim 90$ & 28 & 9 & 32.14 & 8.83 & 65 & 12 & 18.46 & 4.81 & 13.68 & 10.04 & 1.363 \\
\hline & $90 \sim 95$ & 1 & 1 & 100.00 & 0 & 2 & 0 & 0 & 0 & 0 & 0 & 0 \\
\hline & $\mathrm{MR} / \mathrm{S}_{\mathrm{MR}}$ & & & & & & & & & & & 0.492 \\
\hline \multirow{6}{*}{6} & $50 \sim 60$ & 20 & 2 & 10.00 & 6.71 & 36 & 10 & 27.78 & 7.47 & -17.78 & 10.04 & -1.771 \\
\hline & $60 \sim 70$ & 136 & 48 & 35.29 & 4.10 & 113 & 32 & 28.32 & 4.24 & 6.97 & 5.90 & 1.181 \\
\hline & $70 \sim 80$ & 132 & 51 & 37.50 & 4.21 & 154 & 31 & 20.13 & 2.63 & 17.37 & 4.96 & 3.502 \\
\hline & $80 \sim 90$ & 20 & 5 & 25.00 & 9.68 & 56 & 16 & 28.57 & 6.04 & -3.57 & 11.49 & -0.311 \\
\hline & $90 \sim 95$ & 0 & 0 & 0 & 0 & 0 & 0 & 0 & 0 & 0 & 0 & 0 \\
\hline & $\mathrm{MR} / \mathrm{S}_{\mathrm{MR}}$ & & & & & & & & & & & 1.040 \\
\hline \multirow{6}{*}{7} & $50 \sim 60$ & 19 & 4 & 21.05 & 9.35 & 27 & 2 & 7.41 & 5.04 & 13.64 & 10.61 & 1.286 \\
\hline & $60 \sim 70$ & 120 & 33 & 27.50 & 4.08 & 111 & 29 & 26.13 & 4.17 & 1.37 & 5.84 & 0.235 \\
\hline & $70 \sim 80$ & 123 & 53 & 43.08 & 4.47 & 128 & 31 & 24.22 & 3.79 & 18.86 & 5.86 & 3.218 \\
\hline & $80 \sim 90$ & 29 & 12 & 41.38 & 9.14 & 38 & 21 & 55.26 & 8.07 & -13.88 & 12.19 & -3.139 \\
\hline & $90 \sim 95$ & 0 & 0 & 0 & 0 & 0 & 0 & 0 & 0 & 0 & 0 & 0 \\
\hline & $\mathrm{MR} / \mathrm{S}_{\mathrm{MR}}$ & & & & & & & & & & & 1.440 \\
\hline
\end{tabular}




$\bar{I}$\begin{tabular}{r|r|r|r|r|r|r|r|r|r|r|r}
$50 \sim 60$ & 37 & 20 & 54.05 & 8.19 & 53 & 34 & 64.15 & 6.59 & -10.10 & 10.51 & -0.961 \\
$60 \sim 70$ & 244 & 136 & 55.74 & 3.18 & 215 & 93 & 43.26 & 3.38 & 12.48 & 4.64 & 2.689 \\
$70 \sim 80$ & 226 & 122 & 53.98 & 3.31 & 322 & 138 & 42.86 & 2.76 & 11.12 & 4.31 & 2.580 \\
$80 \sim 90$ & 57 & 33 & 57.89 & 6.54 & 106 & 51 & 48.11 & 4.85 & 9.78 & 8.14 & 1.201 \\
$90 \sim 95$ & 1 & 1 & 100.00 & 0 & 4 & 4 & 100.00 & 0 & 0 & 0 & 0 \\
\hline $\mathrm{MR} / \mathrm{S}_{\mathrm{MR}}$ & & &
\end{tabular}

\begin{tabular}{|c|c|c|c|c|c|c|c|c|c|c|c|c|}
\hline \multirow{2}{*}{ 歯 } & \multirow{2}{*}{ 年 令 層 } & \multicolumn{4}{|c|}{ 男 } & \multicolumn{4}{|c|}{ 女 } & \multicolumn{3}{|c|}{ 男 } \\
\hline & & T.exi. & $\begin{array}{c}\text { A1. P. } \\
\text { T. }\end{array}$ & p (\%) & $\mathrm{Sp}(\%)$ & T.exi. & $\begin{array}{c}\text { A1.P. } \\
\text { T. }\end{array}$ & $\mathrm{p}(\%)$ & $\mathrm{Sp}(\%)$ & $\mathrm{d}(\%)$ & $\operatorname{Sd}(\%)$ & $\mathrm{d} / \mathrm{Sd}$ \\
\hline \multirow{6}{*}{$\overline{2}$} & $50 \sim 60$ & 35 & 18 & 51.42 & 8.44 & 55 & 33 & 60.00 & 6.61 & -8.58 & 10.72 & -0.800 \\
\hline & $60 \sim 70$ & 267 & 124 & 46.44 & 3.05 & 258 & 109 & 42.25 & 3.07 & 4.19 & 4. 33 & 0.968 \\
\hline & $70 \sim 80$ & 275 & 143 & 52.00 & 3.01 & 346 & 141 & 40.75 & 2.64 & 1.25 & 4.01 & 0.312 \\
\hline & $80 \sim 90$ & 65 & 39 & 60.00 & 6.08 & 141 & 59 & 41.84 & 4. 15 & 18.16 & 7.36 & 2.467 \\
\hline & $90 \sim 95$ & 1 & $I$ & 100.00 & 0 & 4 & 4 & 100.00 & 0 & 0 & 0 & 0 \\
\hline & $\mathrm{MR} / \mathrm{S}_{\mathrm{MR}}$ & & & & & & & & & & & 1.178 \\
\hline \multirow{6}{*}{$\overline{3}$} & $50 \sim 60$ & 35 & 14 & 40.00 & 8. 28 & 48 & 28 & 58.33 & 7. 12 & -18.33 & 10.92 & -1.678 \\
\hline & $60 \sim 70$ & 342 & 136 & 39.77 & 2.65 & 276 & 77 & 27.90 & 2.70 & 11.87 & 3.79 & 3. 132 \\
\hline & $70 \sim 80$ & 385 & 141 & 36.62 & 2.46 & 414 & 127 & 30.68 & 2.27 & 5.94 & 3. 35 & 1.773 \\
\hline & $80 \sim 90$ & 91 & 28 & 30.77 & 4.84 & 171 & 46 & 26.90 & 3.34 & 3.87 & 5.88 & 0.658 \\
\hline & $90 \sim 95$ & 5 & 4 & 80.00 & 17.88 & 5 & 4 & 80.00 & 17.89 & 0 & 20.79 & 0 \\
\hline & $\mathrm{MR} / \mathrm{S}_{\mathrm{MR}}$ & & & & & & & & & & & 1.554 \\
\hline \multirow{6}{*}{4} & $50 \sim 60$ & 28 & 6 & 21.42 & 7.76 & 51 & 8 & 15.69 & 5.09 & 5.73 & 9.28 & 0.617 \\
\hline & $60 \sim 70$ & 263 & 50 & 19.01 & 2.42 & 242 & 42 & 17.36 & 2.44 & 1.65 & 3. 44 & 0.479 \\
\hline & $70 \sim 80$ & 272 & 67 & 24.63 & 2.61 & 322 & 66 & 20.50 & 2.25 & 4. 13 & 3. 45 & 1.197 \\
\hline & $80 \sim 90$ & 80 & 17 & 21.25 & 4.58 & 8 & 29 & 22.66 & 3.70 & -1.41 & 5.89 & -0.239 \\
\hline & $90 \sim 95$ & 4 & 2 & 50.00 & 25.00 & 5 & 0 & 0 & 0 & 50.00 & -25.00 & 2.000 \\
\hline & $\mathrm{MR} / \mathrm{S}_{\mathrm{MR}}$ & & & & & & & & & & & 1.622 \\
\hline \multirow{6}{*}{5} & $50 \sim 60$ & 25 & 4 & 16.00 & 7.33 & 33 & 2 & 6.06 & 4.15 & 9.94 & 8.43 & 1.179 \\
\hline & $60 \sim 70$ & 207 & 43 & 20.77 & 2.82 & 171 & 37 & 21.64 & 3.15 & -0.87 & 4.23 & -0.206 \\
\hline & $70 \sim 80$ & 209 & 47 & 22.48 & 2.89 & 210 & 34 & 16.19 & 2.54 & 6.29 & 3.86 & 1.629 \\
\hline & $80 \sim 90$ & 54 & 17 & 31.48 & 6.32 & 73 & 26 & 3562 & 5.61 & -4.14 & 8.45 & -0.489 \\
\hline & $90 \sim 95$ & 2 & 2 & 100.00 & 0 & 3 & 1 & 33.33 & 27.22 & 66.67 & 27.22 & 2. 449 \\
\hline & $\mathrm{MR} / \mathrm{S}_{\mathrm{MR}}$ & & & & & & & & & & & 1.824 \\
\hline
\end{tabular}




\begin{tabular}{l} 
表25 男女別年代別歯別 (Al. Py. T./T.exi.) 率之その差 \\
\hline \hline \multirow{2}{*}{ 歯 }
\end{tabular}

6. Al.P.T. $/$ T.exi率 $(\%)$

歯槽膿漏歯数が見有歯数に対する割合で, 男女別年代 別各歯の成績は，表22〜25の通りである.

\section{上 顎}

中切宷 : 男は26.9\%〜28.9\%, 女は9.1\%〜10.3\%.

側切歯男は11.1\%〜31.4\%，女は7.9\%〜13.9\%.

犬蒾：男は9.4\%〜25.0\%, 女は9.5\%〜25.2\%.

第一小罒歯：男は8.3\%〜26.3\%，女は $5.3 \% \sim 10.3$ $\%$.

第二小柬：男は12.5\%〜32.1\%，女は $12.1 \% 〜 18.5$ $\%$.

第一大囦㐘：男は10.0\%〜25.0\%，女は27.8\%〜28.6 \%.

第二大田菌：男は21. 1\%〜 41.4\%，女は 7.4\%〜55.3 $\%$.

\section{下 顎}

中切歯：男は54.1\%〜57.9\%，女は64.2\%〜48.1\%. 側切歯：男は51.4\%〜60.0\%，女は60.0\% 41.8\% 犬歯：男は40.0\%〜30.8\%，女は58.3\%〜26.9\%.

第一小罒囦：男は21.4\%〜21.3\%，女は15.7\%〜22.7 \%.

第二小妇㐘：男は16.0\%〜31.5\%, 女は6.1\%〜35.6 $\%$.

第一大歯：男は5.0\%〜 30.6\%, 女は $4.0 \% \sim 4.6$ $\%$.

第二大扫歯：男は5.9\%〜8.7\%, 女は4.0\%〜4.6\%.

第二大四歯：男は5.9\%〜8.7\%，女は 15.4\%〜15.8
9.

上下顎各歯とも現有歯数が減少しているので，正しい 判定は困難である。

\section{む す び}

老人ホーム入居中の50才〜95才の高令者のう歯の加療 歯について，その内訳，すなわち，義雬，金属冠霜执上 び充填歯などが男女別年代別各䨑における状態を統計的 に観察した。 その結果はつぎの通りである.

1.義電 $/$ F T率 $(\%)$ : 各歯亡も男女間の差は著し くない，男女のいずれの歯す増令につれて増し，F T うち、执よそ80〜100\%が義歯である。

2. 金属冠歯 $/$ F T 率（\%）：男女之もF Tのうち, 金属冠歯は 20\%〜0 \%で増令につれて減少し，男女間の 差はほとんよ゙ない。

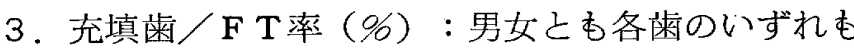
きわめて低率である。増令による差もほとんどない。

4. 充填歯 /DMF T率（\%）：男女टも各歯のいす れ65\%以下のきわめてわずかで，男女間の差，増令に よる差はほとんどない.

5. M T $\rightarrow$ F T $/ \mathrm{M} \mathrm{T}$ 率（\%）：男女亡屯上下顎各粦 は60\%〜50\%は，䘫失歯のまま，未処置画である.

6. Al.P.T/T. exi 率（\%）：男女之も上下頻の同各 歯間では，下顎が上顎より高率で，増令的差はない。

稿を終るに当り，指導と校閲された荷宮教授に謝意を 表す。 


\section{引用 文 献}

1. 荷宮文夫 ; 日満両国兵員の口腔診査成績 : 臨床歯 科, 14, 1-22, (1942).

2. 大和寅雄 ; 北九州成人歯牙の健否 : 九州㐘会誌, 8, 32-37, (1954).

3. 柿沼弘二；居住地を異にした住民の菡牙加療状態よ
り観た歯科衛生学的研究 (永久歯) III成人の噒歯の 加療状態 : 歯学, 48, 207-245, (1960).

4. 満下静一; 福岡市成人の满蝕 曜患状態: 九州 歯会 誌, 17, 15-29, (1963).

5. 滝口親尚；養老院収容者のう歯の加療状態（会）： 九州䨑会誌, 23, 179, (1969). 